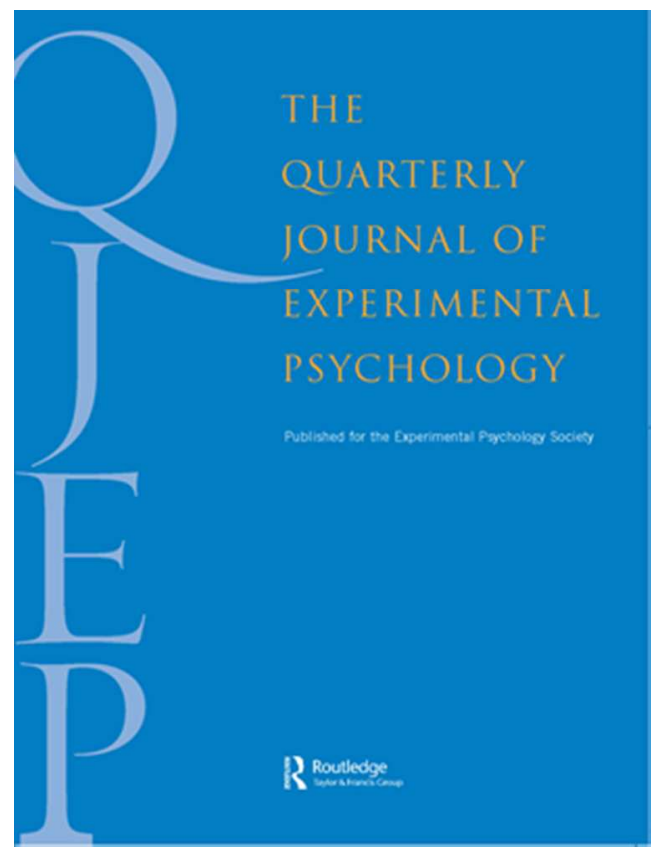

\title{
Evidence for the contribution of a threshold retrieval process to semantic memory
}

\begin{tabular}{|r|l|}
\hline Journal: & Quarterly Journal of Experimental Psychology \\
\hline Manuscript ID & QJE-STD 15-229.R1 \\
\hline Danuscript Type: & Standard Article \\
\hline Complete List of Authors: & $\begin{array}{l}\text { Kempnich, Maria; University of St Andrews, School of Psychology \& } \\
\text { Neuroscience } \\
\text { Urquhart, Josephine; University of St Andrews, School of Psychology \& } \\
\text { Neuroscience } \\
\text { O'Connor, Akira; University of St Andrews, School of Psychology \& } \\
\text { Neuroscience } \\
\text { Moulin, Chris; University of Bourgogne, , France, Laboratoire d'Etude de } \\
\text { l'Apprentissage et du Développement }\end{array}$ \\
\hline Keywords: & \begin{tabular}{l} 
recollection, memory, semantic memory, word recognition \\
\hline
\end{tabular} \\
\hline
\end{tabular}


THRESHOLD RETRIEVAL IN SEMANTIC MEMORY

\title{
Title
}

Evidence for the contribution of a threshold retrieval process to semantic memory

\author{
Authors \\ Maria Kempnich*, School of Psychology \& Neuroscience, University of St. Andrews, \\ Scotland \\ Josephine A. Urquhart*, School of Psychology \& Neuroscience, University of St. Andrews, \\ Scotland \\ Akira R. O'Connor, School of Psychology \& Neuroscience, University of St. Andrews, \\ Scotland \\ Chris J.A. Moulin, LPNC CNRS 5105, Université Grenoble Alpes, France \\ * Maria Kempnich and Josephine Urquhart made equally important contributions to this \\ article and should be recognised as joint first authors.
}

\section{Corresponding Author}

Akira O'Connor, School of Psychology, University of St Andrews, St Mary's College, South Street, St Andrews, Fife, KY16 9JP, Scotland, UK. Email aro2@st-andrews.ac.uk

\begin{abstract}
Acknowledgement
Maria Kempnich was supported by the University of St Andrews University Research Internship Placement Scheme and a Walker Trust Travel Scholarship. Josephine Urquhart was supported by the Economic and Social Research Council 1+3 Scheme.
\end{abstract}

\section{Disclosure Statement}

All authors declare that we have no financial interest and will receive no financial benefit from the direct applications of the research presented in this manuscript. 
THRESHOLD RETRIEVAL IN SEMANTIC MEMORY

\begin{abstract}
It is widely held that episodic retrieval can recruit two processes, a threshold context retrieval process (recollection) and a continuous signal strength process (familiarity). Conversely, and in spite of its importance for everyday memory, the processes recruited during semantic retrieval are less well specified. We developed a semantic task analogous to single-item episodic recognition to interrogate semantic recognition receiver operating characteristics (ROCs) for a marker of a threshold retrieval process. We then fit observed ROC points to three signal detection models: two models typically used in episodic recognition (unequal variance and dual process signal detection models) and a novel dual process recollect-toreject (DP-RR) signal detection model that allows a threshold recollection process to aid both target identification and lure rejection. Given the nature of most semantic questions used here, we anticipated the DP-RR model would best fit the data obtained from our semantic task. In Experiment 1 (506 participants), we found evidence for a threshold retrieval process in semantic memory, with overall best fits to the DP-RR model. In Experiment 2 (316 participants), we found within-subjects estimates of episodic and semantic threshold retrieval to be uncorrelated, suggesting the relationship between the analogous memory processes is not straightforward. Our findings add weight to the proposal that semantic and episodic memory are served by similar dual process retrieval systems, though the relationship between the two threshold processes needs to be more fully elucidated.
\end{abstract}

Keywords: recollection, memory, semantic memory, word recognition 


\section{THRESHOLD RETRIEVAL IN SEMANTIC MEMORY}

Cognitive and neuroscientific evidence indicates that two distinct retrieval processes play a role in episodic recognition: familiarity and recollection (for reviews, see Vilberg \& Rugg, 2008, and Yonelinas, 2002). Familiarity involves an interrogation of memory strength, a continuum along which old and new items (targets and lures respectively) elicit a simple memorial response. An episode recognised on the basis of familiarity alone will not yield any contextual evidence that it is old, merely the awareness that it relates to an experience from the past. Recollection on the other hand, provides context in the form of evidence retrieved to support the recognition judgement e.g. "I am certain that this is the road I travelled with my parents when we were on holiday as I remember stopping at that picnic area."

Recollection is typically conceptualised as a 'threshold' process, not on a graded continuum like familiarity, but with contextual information either being successfully retrieved or not.

Recollection that occurs during recognition of a presented item typically indicates unambiguously that the item is a target (Yonelinas, 2001; though there are exceptions, e.g. Payne, Elie, Blackwell \& Neuschatz, 1996). This is because such target-driven recollection brings to mind associative details encoded during study - details which it would not be possible to recollect were the item a lure. The absence of recollection during such trials however, does not necessarily signify that the currently judged item is a lure - just because one fails to retrieve supporting context, that does not rule out the possibility that an item is a target for which context was not encoded or is currently unavailable. Because episodic recognition tests tend to use cues that do not lead to identification of a single item, it is generally not possible to use recollection to aid rejection of a lure. For example, just because one recollects details associated with 'bush', that does not indicate that one can therefore not have encountered the currently presented 'lens'. Hence, in typical episodic recognition tasks, the threshold process of recollection aids only the identification of targets, and in so doing lends accompanying recognition judgements a high degree of subjective confidence. The continuous process of familiarity on the other hand, can aid the identification of both lures and targets, and does so across the full range of subjective confidence. 
THRESHOLD RETRIEVAL IN SEMANTIC MEMORY

There remains some debate about the contribution of recollection to episodic retrieval (see Dunn, 2004). For example Shiffrin and Steyvers' (1997) REM computational model advances a number of previous models to predict ROC shapes without requiring this process. Meanwhile, Mickes, Wixted \& Wais (2009) posit that recollection is not an 'all-ornone' high-threshold process, but that it is graded in much the way that we have described familiarity. Nevertheless, the dual process nature of episodic retrieval has been largely supported by results from a range of cognitive paradigms, including the 'remember-know' (RK) procedure, process dissociation (PD), and receiver-operating characteristics (ROCs; for a review see Yonelinas, 2002). Whilst the RK procedure has its origins in Tulving's (1985) fractionation of declarative memory into episodic content which can be "(R)emembered", and semantic content which is "(K)nown", it is now widely used to differentiate remembered recollective content from known familiar content (e.g. Gardiner, 1988; Koen \& Yonelinas, 2016). It requires participants to introspect on the subjective quality of their episodic memory and approaches this from the position that the dual process account is correct (participants are required to understand the qualitative distinction between $\mathrm{R}$ and $\mathrm{K}$ responses before they can make them). PD does not require participants to introspect on their retrieval processes, but asks them to make judgements in which they either include all items they recognise or exclude some, which it is assumed can only be done using the context brought to mind via recollection (Jacoby, 1991). Similarly, ROC analyses make even fewer theoretical assumptions at the data collection stage and so are less predisposed to favour dual process accounts when adjudicating between competing accounts of episodic recognition memory. As outlined in detail below, ROC analyses fit theoretically-specified curves to observed data on the assumption that the most accurate account of the memory processes will provide the best fits overall (see Arndt \& Reder, 2002, for a lucid account of this method; also Yonelinas, 1994).

Semantic memory recognition processes underpin a variety of real world tasks and 
behaviours: e.g. Does the word 'tortuous' mean twisty? Is this calf pain a result of plantar fasciitis? Is the brown wire in my plug live? Yet given the vast range of episodic recognition measures which could be repurposed for its investigation, it is surprising how little methodological crossover there is from episodic to semantic memory research. Interestingly, a number of noteworthy studies drawing on methodological crossover from episodic to semantic domains have used famous names as stimuli.

Bowles, Harlow, Meeking and Köhler (2012) conducted two experiments in which they used $\mathrm{ROC}$ fits to investigate the retrieval processes characterising the identification of famous compared to fictional names. In comparing models with different combinations of parameters, they found that ROC differences across their experiments could be best accounted for by model that varied two parameters, the displacement of the target distribution and either the standard deviation of the target distribution or the displacement of an additional lure distributing representing a higher baseline familiarity for famous names (target distribution displacement and standard deviation are explained in greater depth below). Bowles and colleagues found no benefit, beyond what would be expected from including an additional parameter, of including a parameter modelling recollection. Waidergoren, Segalowicz and Gilboa (2012) used a different methodology, a semantic PD procedure, whereby participants classified people as famous or nonfamous and dead or alive. Contrary to Bowles and colleagues' (2012) ROC findings, Waidergoren et al found that their PD data could be best accounted for through the contribution of two processes: a signal strength-based process and a more effortful, contextually rich process-analogous to episodic familiarity and recollection respectively. Data from this PD procedure suggests that dual processes may contribute to systems at play in semantic retrieval, and indeed, this is implicit in later work by Bowles and Köhler (2014). In a semantic task assessing recognition of famous names, Bowles and Köhler identified names which participants termed 'familiaronly'-names for which participants could not retrieve any additional context. The authors found that, although the 'familiar-only' status suggests no additional stimulus information 


\section{THRESHOLD RETRIEVAL IN SEMANTIC MEMORY}

should be recovered, participants were able to perform above chance when given a forcedchoice semantic task (identifying the occupation associated with the name). Importantly to their approach, in using terms aligned to episodic recognition research, Bowles and Köhler suggest that a more complete semantic retrieval would involve a process episodic memory researchers would deem analogous to recollection.

If a dual process account generalised to all semantic memory retrieval, convergent evidence for it could also be evident using ROC analyses. To test memory models against ROC data, theoretically-determined ROC curves are fit to points plotted from old/new and confidence responses to recognition tests, representing the cumulative proportion of targets ( $y$-axis) and lures ( $x$-axis) given judgements from "high confidence old" (bottom-left of the ROC) through to "high confidence new" (top-right). Episodic ROCs based on single-item recognition tasks typically suggest a $y$-axis intercept above zero and an asymmetry about the diagonal joining points $[0,1]$ and $[1,0](y=1-x$; see Figure 1B). Episodic dual process theories accommodate this ROC shape by incorporating the selective advantage to target identification that threshold recollection offers. This takes the form of the parameter, $R$, specifying the degree to which the y-axis intercept falls above 0 i.e. the proportion of targets which recollection unambiguously identifies as "old", at no cost to the misidentification of lures. As would be expected of parameter estimates from this method, convergence with RK and PD methods is established (e.g. Koen \& Yonelinas, 2016; Yonelinas, Dobbins, Szymanski, Dhaliwal \& King, 1996; Yonelinas, Kroll, Dobbins, Lazzara \& Knight, 1998). Extrapolating from these episodic memory findings to the current subject of investigation, and based on Waidergoren and colleagues' (2012) PD-derived evidence for a semantic recollection-like process, it should be possible to find a corresponding marker of a threshold retrieval process using ROCs constructed from on semantic data.

Two established models to which we fit ROCs obtained from semantic recognition are standard models within the episodic recognition memory literature: the unequal variance 


\section{THRESHOLD RETRIEVAL IN SEMANTIC MEMORY}

(UEV) signal detection model; and the previously described dual process (DP) signal detection model. The UEV model is a single process model (i.e. does not assume the existence of a recollection process) which accommodates typical episodic recognition ROCs by allowing the target distribution dispersion to vary relative to the lure distribution dispersion (Heathcote, 2003; Ratcliff, Sheu \& Gronlund, 1992). Thus, it formalises the displacement of the target distribution $\left(d^{\prime}\right)$, and its standard deviation $(\sigma$; see Figure $1 \mathrm{~A})$. When $\sigma$ exceeds the lure distribution standard deviation, the proportion of hits generally increases relative to the proportion of false alarms. Under these circumstances, the ROC will extend from $[0,0]$ to $[1,1]$, but display an asymmetry about the diagonal $(y=1-x ;$ i.e. the dotted line that extends from $[0,1]$ to $[1,0]$ in Figure $1 \mathrm{~A})$. When represented in $z$-space, the UEV model yields lines of varying intercept and gradient. When fitting an UEV model ROC to data based on 6 degrees of confidence, 7 parameters can vary: 5 criterion parameters (one for each confidence boundary), $d^{\prime}$ and $\sigma$.

The DP model accommodates typical episodic recognition ROCs by supplementing a target distribution with the same dispersion as the lure distribution, with the recollection process described previously (Yonelinas, 1994). It therefore formalises a d' parameter and a recollection parameter $(R)$, with $R$ representing the proportion of targets which are not subject to the signal detection process, but are identified as high confidence hits via a second, independent, threshold process (see Figure 1B). In a DP model ROC, the curve will extend from $[0, R]$, usually in the lower left quadrant, to $[1,1]$ in the upper right quadrant, displaying asymmetry about $y=1-x$. When represented in $z$-space, the DP model yields lines with a curve in the lower aspect that corresponds to the magnitude of the R parameter. Under the same conditions as the UEV model, the DP model also has 7 free parameters: 5 criterion parameters, $d^{\prime}$ and $R$.

The above models have different ways of accommodating ROCs asymmetry associated with a higher proportion of high confidence target identifications than lure rejections. 


\section{THRESHOLD RETRIEVAL IN SEMANTIC MEMORY}

Nonetheless, they could not accommodate situation where ROC asymmetry was negated by the additional contribution of recollection to the rejection of lures. Such a situation would be unlikely to occur in standard episodic recognition tests (which is undoubtedly why an ROC model that allows for this possibility has not gained traction) but is well described in alternative tasks in which recollecting the target indicated by the cue can aid the rejection of the lure with which the cue is presented (known as a recall-to-reject strategy; e.g. Rotello, Macmillan \& Van Tassel, 2000). For example, in episodic recognition, recollecting information associated with studying 'glass' has no bearing on whether 'cadence' is a target or a lure. This is because the question used to interrogate memory (implicitly, "This word appeared on the previous list, true or false?") refers to as many probes as were studied. A question with only one answer, on the other hand, affords the recollection aiding lure rejection. Whilst this could be enacted in an episodic task, the most straightforward example of this sort of question that is encountered on a day-to-day basis is in the domain of semantic memory. The cue, "Who was the first person to run a mile in under 4 minutes?", could be used to reject the lure "Eric Liddell" with high confidence, if the respondent recalled the target answer Roger Bannister and recollected details consistent with this alternative response. Thus, assuming that recollection can aid semantic memory retrieval, semantic recognition tests of the form described would warrant a modified instantiation of the dual process model for resulting ROC shapes.

The novel third model to which we fit ROCs obtained from semantic recognition was therefore a dual process model modified to incorporate recollection-aided lure rejection. The dual process recollect-to-reject (DP-RR) signal detection model, uses the same parameters as the classic DP model but the $R$ parameter is operationalised slightly differently (see Formulae 1, adapted from Koen, Barrett, Harlow \& Yonelinas, 2014). DP-RR ROCs show an $x$-axis intercept of $1-R$ at $y=1$ (see Figure 1C). Thus, we propose that semantic retrieval ROCs will, under the demands of this particular task, display evidence of a recollection-like process that both parallels and deviates from that typically observed during episodic 
recognition. In model parameter terms, $R$ represents both the proportion of targets identified with high confidence at no cost to the misidentification of lures and the proportion of lures rejected with high confidence and at no cost to the misidentification of targets. It is important to note that this yoking of the two identification advantages to one parameter ensures that lure rejection must benefit from $R$ as much as target identification does. The benefit of accommodating lure rejection simultaneously constrains the model, only allowing it to fit symmetric ROCs. Thus, in the DP-RR model ROC, the curve will extend from $[0, R]$ to $[1-R, 1]$ with symmetry about $y=1-x$. When represented in $z$-space, the DP-RR model yields lines with curves in both the lower and upper aspects, which correspond to the magnitude of the $\mathrm{R}$ parameter. The number of free parameters, 7 , remains identical to the classic DP model.

$$
\begin{aligned}
& (\text { Bi|target })=R+(1-R) \Phi\left(c_{k}-d^{\prime}, 1\right) \\
& (\text { Bi lure })=(1-R) \Phi\left(c_{k}, 1\right)
\end{aligned}
$$

Note: $B i$ is the $i$ th rating bin, (Bi|target) is the proportion of responses in each bin for targets, (Bi|lure) is the proportion of responses in each bin for lures, $R$ is the recollection parameter, $\Phi$ is the Gaussian cumulative distribution function, $c_{k}$ is the $k$ th criterion placement parameter (where the maximum value of $k$ is equal to $i-1$ ), and $d^{\prime}$ is the familiarity parameter representing the distance between target and lure distributions.

[Formulae 1]

\begin{abstract}
All three models can fully accommodate equal variance single process signal detection ROCs, which are symmetrical about $y=1-x$ and extend from the origin to [1,1], by setting $\sigma$ $=1$ or $R=0$.
\end{abstract}

(Figure 1 about here) 


\section{THRESHOLD RETRIEVAL IN SEMANTIC MEMORY}

The possibility of analogous threshold contributions to semantic and episodic retrieval raises the question of how these processes relate to one another. A core quality of some definitions of episodic recollection is its capacity to stimulate mental time-travel - the re-living of past experiences (Suddendorf \& Corballis, 1997, Tulving, 1985). In contrast, the process of transferring episodic content to semantic memory has been characterised as the stripping away of this episodic specificity (e.g. going from remembering your teacher telling you that the English were defeated by the Scots at the Battle of Bannockburn, to knowing that this is the case without being able to bring to mind how you know; Conway, Gardiner, Perfect, Anderson \& Cohen, 1997; also Klein, 2013). Thus, there are inconsistencies in at least the subjective qualities of recollection and the putative semantic recollection-like process which indicate a range of possible points of divergence. It may be that the threshold retrieval process is unitary, acting on different memory stores, which recover qualitatively different retrieval content. Or it may be that these two processes are entirely dissociable - supported by different neural structures and comparable only in their eventual effects on subjective confidence ratings (c.f. Waidergoren et al, 2012). An obvious exploratory step is to use a within-subjects approach which matches the methods used to estimate the two retrieval processes as closely as possible, to establish whether there is any correspondence in the degree to which semantic and episodic memories are supported by them.

Thus, two questions motivated our research. First, we were interested in whether the semantic recollection-like process reported by Waidergoren et al (2012) would be evident as a threshold process in ROC curves fit to semantic memory retrieval. Second, we wanted to establish whether any semantic threshold process would show a clear relationship with episodic recollection parameters, recovered in an analogous manner. Our starting point was to collect confidence judgements obtained during a single-item semantic recognition task and use these to construct ROCs. To this end, in Experiment 1 we developed and employed a recognition task to assess the semantic retrieval processes recruited to answer general knowledge questions. Our hypothesis was that a recollection-like threshold process would 


\section{THRESHOLD RETRIEVAL IN SEMANTIC MEMORY}

be evident in semantic ROCs. In Experiment 2, we capitalised on the identification of a semantic threshold retrieval process by running within-subjects comparisons of semantic and episodic recognition memory.

\section{EXPERIMENT 1}

\section{METHODS}

\section{Stimuli}

With the aim of constructing ROCs from semantic retrieval data, we developed a test of recognition memory for semantic materials which has the same constraints and procedures as a classic episodic memory recognition task. In episodic tasks there is usually a binary decision, old or new, based on 6 degrees of confidence, ranging from certain old to certain new. Although one tends not to explicitly probe a question in episodic memory tasks, a stimulus word is shown and each trial is essentially of the form: "This word appeared on the previous list, true or false?" (e.g. Donaldson, 1996; c.f. Mill \& O’Connor, 2014). Thus, to parallel this design, our semantic questions were a true/false format with the same 6 confidence points: sure true to sure false. Standard procedure is to probe participants' memories with equal numbers of targets and lures, so we generated a set of questions and provided a true answer for half of the trials and a false answer for the other half.

Stimuli were 500 general knowledge questions generated by the experimenters, covering a wide subject range (see Supplementary Materials A for a complete list). In generating stimuli, we prioritised open-ended questions which allowed the use of a recall strategy as a viable way in which the assessed knowledge could be retrieved e.g. "Which country is associated with haggis?" For each question, we generated one incorrect answer (lure; "Wales") as well as the correct answer (target; "Scotland"). During each memory test, a random sample of 60 questions was selected for each participant. Questions were presented alongside either a target answer (30 trials) or a lure answer (30 trials). The 
THRESHOLD RETRIEVAL IN SEMANTIC MEMORY

experiment was programmed using JavaScript and presented to participants via their internet browsers.

\section{Participants}

506 participants ( 259 men, 239 women, 8 did not disclose sex) completed the online experiment. Participants were recruited via links to the experiment posted on the laboratory website and social networking sites (e.g. Facebook and Twitter). Informed consent was obtained in accordance with the University Teaching and Research Ethics Committee at the University of St Andrews. Of the 500 who disclosed their age, mean reported age was 26.9 years $(S D=10.1)$. We found no differences in sensitivity (equal variance $[E V] d$ ) between the 414 participants who reported that English was their first language $(M=1.06,95 \% \mathrm{Cls}=$ $[1.02,1.09])$ and the 83 participants who reported that it was not $(M=1.03[0.95,1.10])^{1}$. Similarly we found no differences in bias (EV $c)$ over the two groups $(M=-.097[-.120,-.075]$ and $M=-.104[-.154,-.054]$ respectively). We therefore included all participants in subsequent analyses, collapsing across reported first language.

\section{Design and Procedure}

Onscreen instructions were followed by a single test block. A $0.5 \mathrm{~s}$ fixation cross preceded each self-paced test trial. During each test trial, the fixation was replaced by a question presented in $250 \%$ font size at the top of the screen, above an answer (either a target or a lure) presented in $200 \%$ font size (relative font sizes were used to allow for scalable text sizes according to display size/resolution). Below the answer were six response buttons,

\footnotetext{
${ }^{1}$ All preliminary signal detection parameter analyses were conducted on sensitivity $\left(d^{\prime}\right)$ and bias (c) parameters derived from the assumptions of an equal variance signal detection model (Green \& Swets, 1966; Macmillan \& Creelman, 2005). In calculating these parameters, we applied a correction for errorless responding as detailed in Snodgrass and Corwin (1988).
} 


\section{THRESHOLD RETRIEVAL IN SEMANTIC MEMORY}

from left to right: false sure 1 , false probably 2 , false guess 3 , true guess 4 , true probably 5 , true sure 6 . If using a keyboard, participants responded by pressing the corresponding number key. If using a touchscreen device, participants responded by pressing the appropriate button on the screen. After a response had been rendered, the fixation period before the next trial was initiated. Across the entire test, 30 target trials and 30 lure trials were presented with the allocation of question target/lure status being randomised (e.g. the question "The Roman numeral D represents what number?" was equally likely to be presented alongside the target " 500 " as the lure " 50 "). This ensured that the format of the test would not lend itself to the adoption of a bias towards either 'true' or 'false' responding. Once the 60th trial had been responded to, participants were taken to a debrief page, which also provided feedback on their accuracy and confidence.

\section{RESULTS \\ Item Selection}

To acknowledge that participants could look up question answers in a separate tab/window, we excluded responses with response times exceeding $10 \mathrm{~s}$ from all subsequent analyses. We excluded $5.26[4.70,5.82]$ responses per participants, which reduced mean response times from $5.76 \mathrm{~s}[5.57 \mathrm{~s}, 5.94 \mathrm{~s}]$ to $4.91 \mathrm{~s}[4.82,5.00]$.

\section{Model Fits}

To fit each participant to each model, we used standard maximum likelihood estimation (MLE) procedures operationalised in the ROC Toolbox for Matlab (Koen et al, 2014; https://github.com/jdkoen/roc toolbox/releases; we also compared model fits between the DP-RR model and the equal variance signal detection model in Supplementary Materials B). This yielded successful fits to all models in 502 participants $(99.2 \%)$ of the sample. In the additional question-selective analyses detailed below, successful fits were obtained to all models in 500 participants (98.8\%). 


\section{THRESHOLD RETRIEVAL IN SEMANTIC MEMORY}

Figure $2 \mathrm{~A}$ plots the mean observed data against predicted ROCs derived from the mean parameters output by the MLE fitting procedures. The data points are approximately symmetrical about $y=1-x$ and the proximity to the boundaries in the lower left and upper right of the plot are not consistent with an $\mathrm{ROC}$ that tends to $[0,0]$ and $[1,1]$.

For a number of items, participants did not use as much of the response scale as for others. Specifically, these items appeared to be very easy (answered with high confidence as both targets and lures), with the potential that they were biasing the shape of the ROC towards showing markers of a recollection-like process. We therefore conducted an additional ROCfitting procedure on responses to a subsample of questions which encouraged more complete use of the response scale. We eliminated 89 items in which 4 or more of the 12 possible response bins were unused (sure false to sure true [6] across the item's use as a target and a lure [2]). This question exclusion had the effect of decreasing overall EV $d^{\prime}$ from $1.08[1.05,1.12]$ to $0.79[0.76,0.84]$ but had no effect on EV $c$, which was -.123 [-.145, $.101]$ before the exclusion and $-.125[-.149,-.100]$ after. The excluded items were thus confirmed disproportionate contributors of high sensitivity responses. Figure $2 \mathrm{~B}$ plots the question-selective data against predicted ROCs derived from the mean parameters output by the MLE fitting procedures. These data still show symmetry about $y=1-x$, and although the reduced sensitivity is evident as a decreased area under the curve, the first and last ROC points remain inconsistent with a curve that tends to $[0,0]$ and $[1,1]$.

Across both the full dataset and the question-selective subset, the DP-RR model curve shows the most consistent overlap with all of the observed ROC points. The UEV and DP models both show an overshoot of points in the middle range, with this particularly prominent for the UEV model fit to the full dataset (Figure 2A). The UEV and DP models also show an undershoot in the upper right as they both tend to $[1,1]$. (The descriptives summarising the parameters used to generate each ROC curve are shown in Table 1.) The $z R O C s$ for both datasets are also best accommodated by the DP-RR model. The curves at both upper and 


\section{THRESHOLD RETRIEVAL IN SEMANTIC MEMORY}

lower aspects of the line are accommodated by the DP-RR model, but cannot be accommodated by the linear UEV model or the single curve of the DP model.

Given the close correspondence between the full dataset and the question-selective subset, and the risk of biasing our results towards best fitting the DP-RR model, we use only question-selective data in future analyses.

(Figure 2 about here)

(Table 1 about here)

ROC curves and zROC lines based on averaged model parameters do not necessarily best represent the fit/misfit of the models on a per participant basis. We therefore illustrate each participant's model misfit (estimated ROC point position relative to the observed position) for each ROC criterion point in Figure 3. Examination of the scatterplots reveals that the DP-RR model is noisier in its fits than the UEV and DP models, though the overall mean misfit, reflecting the averaged model fits, shows less systematic bias (mean misfit point closer to the origin). To formally asses the absolute misfit at each point, we calculated Euclidean misfit distances (shown in Figure 4) and entered these values into a 3 (model: UEV; DP; DPRR) $\times 5$ (ROC point) ANOVA. As suggested by the scatterplots, there was a main effect of model, $F(2,1010)=52.57, p<.001, \eta_{p}^{2}=.094$, with the DP-RR model showing greatest absolute misfit $(M=.044,[.042, .047])$ relative to the DP $(M=.037,[.036, .039])$ and UEV $(M$ $=.035,[.033, .036])$ models. (There was also a significant main effect of ROC point, $F(4$, $2020)=107.01, p<.001, \eta_{p}{ }^{2}=.175$, and a significant interaction, $F(8,4040)=117.22, p<$ $.001, \eta_{p}^{2}=.188$.) These two illustrations suggest that, whilst the DP-RR model's shape appears to best accommodate group data from the semantic memory task, misfit on the participant level may be higher for the novel model compared to the two established models. We now turn to analysis of the fit statistics to assess whether misfit is indeed greater for the DP-RR model than the others. 
THRESHOLD RETRIEVAL IN SEMANTIC MEMORY

(Figure 3 about here)

(Figure 4 about here)

Log likelihood $(L L)$ parameters represent the probability of the data given the parameter estimates. They are always negative, with more positive (closer to 0 ) values indicating better model fits. We calculated $L L$ for each participant (see Table 1 for descriptives) and entered the parameters for the question-selective dataset into a three-way (model: UEV, DP, DP$\mathrm{RR}$ ) repeated measures ANOVA (identical analysis of the full dataset yielded revealed the same effects). There was a significant difference in $L L$ according to model, $F(2,998)=69.82$, $p<.001, \eta_{p}{ }^{2}=.123$, with the DP-RR model yielding better (more positive) fits than the other two models. This advantage in the fit statistics was borne out in the proportion of participants for whom the DP-RR model was best fitting, compared to the UEV and DP models: .538, .318 and .144 respectively, $X^{2}(2)=116.96, p<.001$. It should be noted that the UEV and DP models both typically account for $\sim 99.9 \%$ of variance in standard episodic ROCs (e.g. O'Connor, Guhl, Cox \& Dobbins, 2011), meaning that these DP-RR advantages are noteworthy.

The majority of analyses support the DP-RR model as best characterising semantic memory retrieval within these recognition tests. The proximity of points to the upper and left bounds in the ROC, alternatively represented by the curve at upper and lower aspects of the $z R O C$ are not well accommodated by either the UEV or DP models (Figure 2). Conversely, the DPRR model, which affords recollection-like benefit to both the high confidence identification of targets and the high confidence rejection of lures, best estimates the parameters characterising retrieval here. Although fits to the DP-RR model are noisier than to competing models, they result in less systematic deviation from the observed data (Figures 3 and 4) and as a result yield significantly better fit parameters than the UEV and DP models. In sum, Experiment 1 demonstrates that semantic retrieval does indeed display an ROC marker of a 


\section{THRESHOLD RETRIEVAL IN SEMANTIC MEMORY}

recollection-like threshold process (albeit operationalized slightly differently to episodic recollection), and we proceed to Experiment 2 with the aim of using the DP-RR model to best recover semantic retrieval threshold parameters to for within-subjects comparison with episodic retrieval threshold parameters.

\section{EXPERIMENT 2}

We next looked for indication of whether semantic and episodic threshold retrieval share the same underlying process - whether the semantic threshold retrieval process is comparable to recollection from to episodic memory. To this end, we administered the semantic recognition test from Experiment 1 alongside an analogous episodic recognition task. A correlation between the recovered semantic and episodic threshold parameters could indicate some association which could be explored with further analyses. Experiment 2 also allowed us to attempt to replicate the findings from Experiment 1 using an independent sample. Thus, we first compared recognition fits to the three models, before using the model parameters recovered from these fits to search for an association in threshold parameters across tasks.

\section{METHODS}

\section{Stimuli}

As in Experiment 1, Experiment 2 was programmed using JavaScript and presented to participants via their internet browsers.

Semantic Test. The 411 general knowledge questions used in the question-selective subset of Experiment 1 were used in the semantic test. For each participant, a random sample of 50 semantic questions (25 targets, 25 lures) was drawn from this question pool.

Episodic Test. A word pool comprising 2200 singular, common nouns from the English Lexicon Project (Balota et al., 2007) was used in the episodic test. A Hyperspace Analogue 


\section{THRESHOLD RETRIEVAL IN SEMANTIC MEMORY}

to Language (HAL) frequency high-pass cut-off of 7.70 served to exclude highly distinctive items (final word list characteristics: mean HAL frequency $=8.98$, mean word length $=7.24$, mean number of syllables $=2.43$ ). For each participant, a random sample of 100 episodic memory questions was administered in a single study-test block. Fifty words presented at both study and test (targets) and 50 words were presented only at test (lures).

\section{Participants}

316 participants (115 men, 187 women, 14 did not disclose sex) completed the online experiment. Recruitment and ethics procedures were identical to those in Experiment 1. Of the 301 who disclosed their age, mean reported age was 27.7 years $(S D=11.8)$. Once again, we found no differences in EV $d^{\prime}$ between the 240 participants who reported that English was their first language and the 62 participants who reported that it was not (semantic: first language $M=.684[.624, .744]$, second language $M=.692[.581, .803]$; episodic: first language $M=2.00[1.87,2.13]$, second language $M=2.10[1.92,2.27])$. Similarly we found no differences in EV c over the two memory tests (semantic: first language $M=-.146[-.183,-.108]$, second language $M=-.178[-.256,-.100]$; episodic: first language $M=.061[.018, .103]$, second language $M=.125[.022, .228])$. We included all participants in subsequent analyses.

\section{Design and Procedure}

Onscreen instructions were followed by the episodic study-test block, and then the semantic test block. In the episodic study phase, a $0.5 \mathrm{~s}$ fixation cross preceded each self-paced study trial $(\mathrm{RT} M=2.30 \mathrm{~s})$. During each study trial, the fixation was replaced by a word presented in $850 \%$ font size in the middle of the screen. Below the word was a task cue "syllables?" (220\% font), and six response buttons, 1 to $6+$. Participants could use a keyboard or touchscreen (where available) to respond. After a response had been rendered, the fixation period before the next trial was initiated. After 50 study trials, the episodic test phase was initiated. A $0.5 \mathrm{~s}$ fixation again preceded each self-paced test trial. Test words 
THRESHOLD RETRIEVAL IN SEMANTIC MEMORY

( $850 \%$ font) were presented in the middle of the screen, above the task cue "recognition?" (220\% font). The six responses buttons were, from left to right: new sure 1 , new probably 2 , new guess 3 , old guess 4 , old probably 5 , old sure 6 . Once the 100 th trial had been responded to, participants were taken to the self-paced semantic test, which was a slightly shorter version of that described for Experiment 1 (50 rather than 60 trials). The semantic test was followed by a debrief, which provided feedback on participant accuracy and confidence across the two tests.

\section{RESULTS \\ Item Selection}

We excluded responses with response times exceeding 10s. In the semantic test, we excluded $4.97[4.33,5.60]$ responses per participants, which reduced mean response times from $6.16 \mathrm{~s}$ [5.91 s, $6.41 \mathrm{~s}]$ to $5.18 \mathrm{~s}$ [5.06 s, $5.30 \mathrm{~s}]$. For the episodic test, although participants would not have been able to look up the answers online, for consistency we applied the same response exclusion criteria, excluding $0.67[0.50,0.85]$ responses per participant, which reduced overall response times from $2.10 \mathrm{~s}[2.01 \mathrm{~s}, 2.18 \mathrm{~s}]$ to $2.00 \mathrm{~s}[1.94$ $\mathrm{s}, 2.07 \mathrm{~s}]$.

The overall semantic test EV d' of .688 [.630, .745] was lower than in the question selective subset of Experiment 1, suggesting the 411 semantic items used did not result in excessively high sensitivity responses. (Mean EV c was -.176 [-.212, -..140]). We therefore proceeded with the analyses without excluding any additional semantic items.

\section{Receiver Operating Characteristics and Model Fits}

We first addressed how the competing models from Experiment 1 would fit the data obtained in each memory test. We anticipated that the DP-RR model would best fit semantic retrieval responses, whereas one of the established models for episodic recognition would best fit episodic retrieval responses. 
THRESHOLD RETRIEVAL IN SEMANTIC MEMORY

We used an analytic procedure identical to that used in Experiment 1. Successful fits were obtained in 309 participants (98.1\%) for the semantic task and in 280 participants $(88.9 \%)$ for the episodic task. The difference here is likely driven by the difference in $d^{\prime}$ over the two tasks. Mean EV $d^{\prime}$ for the semantic task, $0.70[0.64,0.76]$ was far lower than for the episodic task, $1.99[1.88,2.10]$. Although this sensitivity disparity is potentially problematic when adjudicating model fits, we restrict the bulk of our analyses below to sensitivity-matched subsamples.

Figure $5 \mathrm{~A}$ uses the whole sample to plot the average observed ROC points against average predicted ROC curves for semantic and episodic tasks. Once again, for the semantic task, the points are approximately symmetrical about $y=1-x$ and inconsistent with an ROC that tends to $[1,1]$. In contrast, the episodic task ROC shows points that could be from an ROC that tends to $[1,1]$. To best ensure that subsequent findings were attributable to the tasks themselves and not differences in sensitivity associated with each task outlined above, for the remainder of this section, we report analyses applied to subsamples whose sensitivity were comparable (though descriptive for the full sample are shown in Table 2 and all patterns of significance were almost identical across full and sensitivity-matched subsamples). For the semantic task, we used a high-pass filter of 0.875 , applied to EV $d$ ', yielding 109 participants with mean EV $d^{\prime}$ of 1.24 [1.18, 1.30]. For the episodic task, we used a low-pass filter of 1.925 , applied to the EV d' estimate, yielding 108 participants with mean EV $d^{\prime}$ of $1.26[1.07,1.44]$. Figure 5B plots the average observed ROC points and average predicted ROCs from fits to these subsamples. Once again, the proximity of semantic ROC points to the top boundary, suggests a better fit for the DP-RR model to the semantic data, though the best-fitting model for the episodic data is less obvious.

(Figure 5 about here) 
THRESHOLD RETRIEVAL IN SEMANTIC MEMORY

We first examine analyses of data from the semantic recognition task. Whilst the DP-RR model appears to best fit the data on a group-averaged level, the misfit scatterplot in Figure 6 once again shows that the DP-RR fits are noisier than those for the competing models, though with less systematic deviation (as demonstrated by reduced deviation from $[0,0]$ in the mean plots). Absolute misfit distances (Figure 8 Panel A) in a 3 (model) x 5 (ROC point) ANOVA demonstrated a main effect of model, $F(2,216)=19.79, p<.001, \eta_{p}{ }^{2}=.155$, with DP-RR showing greatest absolute misfit $(M=.039,[.035, .043])$ relative to the $\mathrm{DP}(M=.034$, $[.031, .037])$ and UEV $(M=.028,[.025, .030])$ models. (There was also a significant main effect of ROC point, $F(4,432)=17.65, p<.001, \eta_{p}{ }^{2}=.140$, and a significant interaction, $F(8$, $864=13.29, p<.001, \eta_{p}^{2}=.110$.)

(Figure 6 about here)

In spite of the misfit distances, $L L$ fit statistics (Table 2) again showed that the semantic data within the sensitivity-matched sample are best accommodated by the DP-RR model. Entered into a repeated measures ANOVA, a significant effect of model on $L L$ was found, $F(2,216)=10.24, p<.001, \eta_{p}^{2}=.087$, with the DP-RR model yielding better fits than the other two models. This advantage in the fit statistics was borne out in the proportion of participants for whom the DP-RR model was best fitting, compared to the UEV and DP models: $.495, .385$ and .119 respectively, $x^{2}(2)=24.46, p<.001$. Thus, these data from the semantic task in Experiment 2 replicated those of Experiment 1 in ROC shape, misfit distance and model fit.

(Table 2 about here) 


\section{THRESHOLD RETRIEVAL IN SEMANTIC MEMORY}

Moving to the episodic recognition task, group-averaged ROC fits appear more ambiguous as to the best-fitting model, but the misfit scatterplot in Figure 7 shows that the DP-RR fits are again noisier than those for the competing models. This time, and in contrast to the means plots in Figure 6, Figure 7 shows that the DP-RR model yields more systematic misfit (greater mean deviation from $[0,0]$ ) than the competing models. Absolute misfit distances (Figure 8 Panel B) in a 3 (model) x 5 (ROC point) ANOVA yielded a main effect of model, $F(2,214)=19.48, p<.001, \eta_{p}{ }^{2}=.154$, with DP-RR showing greatest absolute misfit $(M=$ $.024,[.020, .027])$ relative to the DP $(M=.017,[.016, .019])$ and UEV models $(M=.016$, $[.014, .018])$. (There was also a significant main effect of ROC point, $F(4,428)=35.10, p<$ $.001, \eta_{p}{ }^{2}=.247$, and a significant interaction, $F(8,856)=18.89, p<.001, \eta_{p}{ }^{2}=.150$.)

(Figure 7 about here)

(Figure 8 about here)

Consistent with the more ambiguous ROC fits, $L L$ fit statistics were less clear-cut for the episodic data. There was no significant effect of model on $L L$ in a repeated-measures ANOVA, $F(2,214)=1.03, p=.360, \eta_{p}{ }^{2}=.009$, and although the UEV model yielded numerically better fits than its competitors, the $L L$ values are all very close. Overall, the DPRR model's advantage in fitting semantic data is lost when applied to episodic data, with the UEV model fitting a greater proportion of participants best, compared to the DP-RR and DP models: $.491, .287$ and .222 respectively, $X^{2}(2)=12.72, p=.002$. These new data from the episodic task in Experiment 2 demonstrate that the DP-RR model is not a generally betterfitting model for all recognition tasks, but is specific in its advantage for certain tasks - in this case to data obtained from the semantic recognition tasks of Experiments 1 and 2.

Having established that DP-RR-recovered threshold process parameters are reliable and specific in quantifying responses to semantic recognition memory responding, we now 


\section{THRESHOLD RETRIEVAL IN SEMANTIC MEMORY}

proceed to test the association between within-subjects semantic and episodic threshold process estimates using the two models that provide such an estimate: the novel DP-RR model within semantic data, and the established DP models within episodic data.

\section{Association between Semantic and Episodic Threshold Process Estimates}

As a preliminary check, we first examined the full sample correlations between EV $d^{\prime}$ and $c$ parameters and mean confidence responses to hits and correct rejections. Within episodic and semantic tasks, we anticipated that: i) $d$ ' would be positively correlated with both hit and correct rejection confidence; and ii) the two confidence means would be positively correlated. We also anticipated that: iii) each of the four parameters would be positively correlated with its cross-domain equivalent. Table 3 (shaded cells) shows that these predictions were largely supported by the data, but there was no correlation across domains between the EV $d^{\prime}$ or the $c$ parameters.

(Table 3 about here)

We then proceeded to the main correlation analysis testing the association between the threshold parameters $(R)$ estimated for semantic and episodic tasks. To do this we identified all participants for whom both the DP-RR model had recovered a fit for their semantic task responses and the DP model had recovered a fit for their episodic task responses. This left 278 participants (88.3\% of the original full sample). In this subsample, mean semantic EV $d^{\prime}$ was $0.69[0.63,0.76]$ and mean episodic EV $d^{\prime}$ was 1.99 [1.88, 2.10].

As a preliminary check, we found no correlation between the equal variance $d$ ' parameters across the two tasks, $r(276)=.031,95 \%$ Cls based on 10000 bootstrapping samples $=[-$ $.066, .121], p=.609$. As in the full sample, in the subsample there was no significant relationship between participants' abilities to discriminate true from false general knowledge questions in the semantic test and their abilities to recognise old from new words in the 


\section{THRESHOLD RETRIEVAL IN SEMANTIC MEMORY}

episodic test. We proceeded to test the correlation between semantic DP-RR and episodic DP $R$ parameters, as an association between the two (such as one driven by a reliance on the same retrieval process) could be hidden by a divergence in other processes contributing to overall sensitivity. No association whatsoever was observed between semantic and episodic R parameters, $r(276)=-.001[-.122, .120], p=.987$, (see Figure 9; there was also no correlation between respective DP-RR and DP $d$ ' parameters recovered using the same fitting procedures $\mathrm{r}[276]=.085[-.048, .215], p=.156)$. In case a true association between threshold parameters was masked by $R$ parameters estimated to be 0 , we removed all participants with DP-RR or DP $R$ parameters less than 0.01 and ran a second correlation, also showing no relationship, $r(153)=.065[-.099, .225], p=.421$. Thus, we found no association between the two threshold processes we propose contribute to semantic and episodic retrieval.

(Figure 9 about here)

\section{DISCUSSION}

We used a novel single-item semantic recognition task to find evidence for a recollection-like threshold retrieval process within semantic memory. In Experiment 1 we found that the DP$\mathrm{RR}$ model, a variation of the dual process model that allows recollection to contribute to both the identification of targets and the rejection of lures, provides better fits to the observed data than the unequal variance single process model and the standard dual process model. In Experiment 2 found the DP-RR model fitting advantage was specific to our semantic test, and does not persist in the standard single-item episodic recognition test. Finally, we used the threshold parameters recovered using these fitting procedures and found there to be no association between the relative magnitudes of the threshold parameters recovered in semantic and episodic recognition. 


\section{THRESHOLD RETRIEVAL IN SEMANTIC MEMORY}

Our experimental task recovered ROCs indicating the presence of a process analogous to episodic recollection in semantic memory. This finding is consistent with that of Waidergoren and colleagues' (2012) study using a semantic process dissociation task, but used an independent experimental paradigm to recover this convergent result. Specific to our procedure, the ROC model that best fit semantic recognition responding incorporated a recollection parameter necessary for dual process accounts of episodic memory (Yonelinas, Aly, Wang \& Koen, 2010). Using the same terms as are used to justify similar patterns in episodic tasks, our results show that semantic memory retrieval includes a process by which we are able to identify answers to questions assessing knowledge as unambiguously true. This process likely draws on the recovery of contextualising information e.g. "I know with high certainty that Canberra is the capital of Australia because i) the capital isn't Sydney, ii) Canberra is in a territory called the Australian Capital Territory, and iii) I remember seeing the Aboriginal Tent Embassy outside Parliament House when I visited Canberra." This third contextual point is an example where episodic recollection can provide context for semantic knowledge, but we argue that the semantic threshold process is not necessarily dependent upon episodic content: we can imagine that a number of different sources of information can bring to bear on recognition decisions. Nonetheless, this raises a potentially important consideration for those looking to extend this finding further. Whereas the mappings of responses to components of dual process episodic memory models are considered fuzzy because of the lack of process purity (high confidence target recognition can be justified by both recollection and familiarity; Wixted, 2007), there is in this case a lack of 'system purity' in the putative dual process semantic memory system. Episodic and semantic content may well be used to justify semantic recollection-like retrieval.

This proposed system impurity revisits a similar crossover in the origins of the episodic dual process account. Tulving (1985) originally intended the RK procedure to differentiate episodic material ( $R$ responses) from semantic material ( $K$ responses). Indeed, such a taxonomy without consideration of more recent work, would have led us to hypothesise that 


\section{THRESHOLD RETRIEVAL IN SEMANTIC MEMORY}

semantic retrieval should recruit only a single process, familiarity. Importantly though, Tulving's system distinction became a process distinction as episodic recognition researchers began to consider these responses qualitatively different, but both within the episodic memory system (e.g. Gardiner, 1988). Taken together, these system and process impurities point to flexible memory arrangements within which content consistent with response justification, regardless of domain, can be amalgamated. As regards our examination of semantic memory processes, a RK procedure requiring participants to give justifications could provide a better indication of the breakdown of episodic and semantic justifications. We can also envisage scenarios in which non-memorial reasoning and problem-solving processes might contribute to responses, and could therefore be considered influential of a memory decision-making system drawing on a range of cognitive processes. In the first instance though, it is clear that Tulving's taxonomy continues to require revision, with mounting evidence that content and processes which would previously have been considered exclusively episodic, weighing in on semantic retrieval too.

A consistent finding across our two experiments is the overall advantage the DP-RR model showed in accommodating the semantic ROC data. Although both dual process models incorporate the threshold process aiding target detection, the key advantage for the DP-RR model is its ability to model the upper intercept as $[1-R, 1]$. This intercept replaces the $[1,1]$ intercept observed in episodic recognition, and is indicative of a high-certainty lure rejection process unique to these particular semantic materials. We propose that this results from the mutual exclusivity of our semantic questions, which afford the following reasoning: "If the answer to the question is Ahab then it cannot also be Ishmael". Such recall-to-reject strategies can apply in episodic memory too, as discussed earlier (e.g. Rotello et al. 2000). These apply especially where one has to differentiate between two familiar stimuli. But, in typical item-by-item tests of episodic recognition memory, the reasoning "'table' was not a studied word, because 'apple' was" does not hold. Thus, recollection-like retrieval contributes to semantic recognition responses but, given the mutual exclusivity of target and 


\section{THRESHOLD RETRIEVAL IN SEMANTIC MEMORY}

lure options for each semantic question, its utility here is two-fold, to confirm targets and to reject lures.

We suggest that this deviation from what would be expected based on standard episodic ROCs is driven by the nature of the semantic task used. If we had used a semantic task for which correct answers were not mutually exclusive, we would likely have observed an asymmetric benefit to targets, and not lures, akin to that observed in episodic recognition. More generally, in considering how to refine the present findings, we believe it is important to disentangle the question format from the memory store interrogated. If it is taken that recollection operates within both semantic and episodic systems, the mutual exclusivity of the cue-probe combination should be what determines whether the DP or the DP-RR best fits data obtained from either system. We contend that responses to general knowledge questions which have more than one answer (e.g. "The following word was invented by Shakespeare:" where any number of words could be correct) would be more likely to be best fit by the DP rather than the DP-RR model (though this also depends on the recollective affordance of the lure probe). Alternatively, an episodic paired-associate recognition task in which retrieval of the target would rule out the lure, would be best fit by the DP-RR task. Such tasks would go some way towards demonstrating the format-dependent utility of a threshold retrieval process in all forms of memory decision-making.

Having found that the overall pattern of results points towards the DP-RR model best fitting the semantic data, it is curious that the same model produces greater absolute misfit distances than its competitors. An insight into why this might be can be found from examination of the correlations between absolute misfit distances across criterion points. There are 10 correlations (C1-C2, C1-C3 ... C4-C5), over which the Experiment 1 grand average correlation $r$ is $.532[.452, .612]$ for the DP-RR model, . $173[.075, .271]$ for DP and $.288[136,441]$ for UEV. That the DP-RR model shows greatest coherence in its misfit could 


\section{THRESHOLD RETRIEVAL IN SEMANTIC MEMORY}

result from it providing fair fits across all points, rather than good fits for most, compared to an excellent/bad fit for the remaining one or two points.

Relatedly, a modification of the DP-RR model which would have improved the absolute misfit as well as the overall fits, would be to remove the yoking of target identification- and lure rejection-aiding recollective processes. Whilst the questions/cues remain identical across target/lure trials, the probes themselves have the potential to elicit differing recollective response-in addition to recall and recollection cued by the question, a target probe may in itself trigger recollection of context that confirms its status, whilst a lure probe may trigger context that disconfirms it as the correct response. Operationalising this in a signal detection model straightforward (indeed, it is provided as a model within Koen et al.'s 2014 ROC toolbox), but it would necessitate an additional parameter relative to the two established models. We wanted to avoid this in the first instance-there are issues with using fit statistics that penalise for additional parameters, see Supplementary Material Band the $L L$ fits suggest that in spite of this constraint, the DP-RR model is largely superior to its competitors in its fits. Both issues remain to be fully elucidated, but should not detract from the overall superiority of the DP-RR model, even in its current form, when it comes to fitting the semantic data.

A criticism of the presented data, which led to knock-on effects for our analyses, concerns the sensitivity discrepancy between the episodic and semantic tests of Experiment 2. Episodic task performance was far higher than semantic performance, meaning that any differences in fits across task could have been attributed to the models' capacities to fit at differing sensitivities, rather than their capacities to fit based on the tasks themselves. Our solution here was to restrict our sample to subsamples with matched sensitivities, and while this overcame the problem of differential sensitivity, it removed the within-subjects strength of the Experiment 2 design. It would have been preferable to have been able to use the same samples for both sets of fits, and this is a design consideration to be borne in mind 


\section{THRESHOLD RETRIEVAL IN SEMANTIC MEMORY}

both for future studies and the interpretation of the correlations between $R$ parameters derived from these two tests.

We found no association between the contributions of semantic and episodic threshold parameters to recognition performance in each domain. Significant $R$-parameter correlations estimated using three different recognition tasks (albeit within the same episodic memory system), have previously been found within subjects (e.g. Koen \& Yonelinas, 2016), suggesting that this approach yields correlations when performance depends on the same underlying process. Thus, it would be tempting to argue that the absence of a relationship across our tasks indicates that the two threshold processes identified are not unitary. The opposite case would have been far easier to make if a significant correlation had been found (though with the caveat that third variables can underpin shared variance in cognition), but it is not possible to argue convincingly that the absence of a correlation indicates the absence of a relationship.

A number of factors, not least the previously discussed sensitivity discrepancy across tests, may have contributed to the present results. The varied nature of the semantic task, compared to the episodic task, may have played a role in masking any association between $R$ parameters. There are vast individual differences in the near limitless domains of semantic knowledge. While the within-subjects tendency to retrieve context to support semantic judgements could be static, if Participant A is only able to draw on very little contextual material to support rejection of a pop music lure, but Participant B's interest in the subject furnishes them with far contextual material, it follows that Participant B will show greater evidence of recollection than Participant A, regardless of their individual tendencies. We can also return to discussion of the system purity of semantic and episodic retrieval to explain any lack of an association. Some semantic questions may have been easier if the participant had reasoned the target as true or the lure as false. For the episodic task, some participants may have been better able to sustain attention to the study list than others, 


\section{THRESHOLD RETRIEVAL IN SEMANTIC MEMORY}

thereby enhancing encoding. Thus, reasoning and attention abilities may contaminate the estimates of $R$, further diluting the chances of finding an association. Greater experimental control could go some way towards eliminating these confounds. For example, there is the intriguing possibility of having participants study artificial semantic material under controlled conditions, which is then tested both episodically and semantically. However, such a procedure lay outwith the realms of the current set of online experiments, and the question of whether the absence of an association indicates the true absence of a mechanistic relationship remains to be answered.

As a starting point for theoretical discussions, our results suggest that semantic and episodic memory systems recruit multiple retrieval processes which show parallels in function. More intriguingly, they open the door to the possibilities of both convergence and divergence within the same threshold process, applied to retrieval from different memory stores. In applying established episodic memory analysis techniques to the study of semantic memory, we have produced further evidence to suggest we should rethink widely held assumptions of how we bring knowledge to mind.

\section{REFERENCES}

Arndt, J., \& Reder, L.M. (2002). Word frequency and receiver operating characteristic curves in recognition memory: evidence for a dual-process interpretation. Journal of Experimental Psychology: Learning, Memory, and Cognition, 28(5), 830-842. http://dx.doi.org/10.1037/0278-7393.28.5.830

Balota, D.A., Yap, M.J., Cortese, M.J., Hutchison, K.A., Kessler,B., Loftis, B., et al (2007). The English lexicon project. Behavior Research Methods, 39, 445-459. http://dx.doi.org/10.3758/BF03193014

Bowles, B., Harlow, I.M., Meeking, M.M. \& Köhler, S. (2012). Discriminating famous from fictional names based on lifetime experience: evidence in support of a signal-detection 
THRESHOLD RETRIEVAL IN SEMANTIC MEMORY

model based on finite mixture distributions. Journal of Experimental Psychology: Learning, Memory, and Cognition, 38, 78-91. http://dx.doi.org/10.1037/a0025198

Bowles, B. \& Köhler, S. (2014). Availability of semantic knowledge in familiar-only experiences for names. Journal of Experimental Psychology: Learning, Memory, and Cognition, 40, 724-737. http://dx.doi.org/10.1037/a0035584

Conway, M.A., Gardiner, J.M., Perfect, T.J., Anderson, S.J. \& Cohen, G.M. (1997). Changes in Memory Awareness During Learning: The Acquisition of Knowledge by Psychology Undergraduates. Journal of Experimental Psychology: General, 4, 393-413. http://dx.doi.org/10.1037/0096-3445.126.4.393

Donaldson, W. (1996). The role of decision processes in remembering and knowing. Memory \& Cognition, 24(4), 523-533. http://dx.doi.org/10.3758/BF03200940

Dunn J.C. (2004) Remember-know: A matter of confidence. Psychological Review, 111, 524-542. http://dx.doi.org/10.1037/0033-295X.111.2.524

Gardiner, J.M. (1988). Functional aspects of recollective experience. Memory \& Cognition, 16, 309-313. http://dx.doi.org/10.3758/BF03197041

Green, D.M., \& Swets, J.A. (1966). Signal detection theory and psychophysics. New York: Wiley.

Heathcote, A. (2003). Item recognition memory and the receiver operating characteristic. Journal of Experimental Psychology: Learning, Memory, and Cognition, 29, 1210 1230. http://dx.doi.org/10.1037/0278-7393.29.6.1210

Jacoby, L.L. (1991). A Process dissociation framework: Separating automatic from intentional uses of memory. Journal of Memory and Language, 30, 513-541. http://dx.doi.org/10.1016/0749-596X(91)90025-F

Klein, S.B. (2013). Making the case that episodic recollection is attributable to operations occurring at retrieval rather than to content stored in a dedicated subsystem of longterm memory. Frontiers in Behavioral Neuroscience, 7:3. http://dx.doi.org/10.3389/fnbeh.2013.00003 
THRESHOLD RETRIEVAL IN SEMANTIC MEMORY

Koen, J.D., Barrett, F.S., Harlow, I.M. \& Yonelinas, A.P. (2014). ROC Toolbox Manual. Davis: The Regents of the University of California.

Koen, J.D. \& Yonelinas, A.P. (2016). Recollection, not familiarity, decreases in healthy ageing: Converging evidence from four estimation methods. Memory, 24, 75-88. http://dx.doi.org/10.1080/09658211.2014.985590

Macmillan, N.A., \& Creelman, C.D. (2005). Detection theory: A user's guide (2nd ed.). New York: Lawrence Erlbaum.

Mickes, L., Wais, P.E. \& Wixted, J.T. (2009) Recollection is a continuous process. Psychological Science, 20, 509-515. http://dx.doi.org/10.1111/j.1467$9280.2009 .02324 . x$

Mill, R.D., \& O'Connor, A.R. (2014). Question format shifts bias away from the emphasised response in tests of recognition memory. Consciousness and Cognition, 30, 91-104. http://dx.doi.org/10.1016/j.concog.2014.09.006

O'Connor, A.R., Guhl, E.N., Cox, J.C. \& Dobbins, I.G. (2011). Some memories are odder than others: Judgments of episodic oddity violate known decision rules. Journal of Memory and Language, 64, 299-315. http://dx.doi.org/10.1016/j.jml.2011.02.001

Payne, D.G., Elie, C.J., Blackwell, J.M. \& Neuschatz, J.S. (1996). Memory illusions: Recalling, recognizing, and recollecting events that never occurred. Journal of Memory \& Language, 35, 261-285. http://dx.doi.org/10.1006/jmla.1996.0015

Ratcliff, R., Sheu, C.-F., \& Gronlund, S.D. (1992). Testing global memory models using ROC curves. Psychological Review, 99, 518-535. http://dx.doi.org/10.1037/0033295X.99.3.518

Rotello, C.M., Macmillan, N.A., \& Van Tassel, G. (2000). Recall-to-reject in recognition: Evidence from ROC curves. Journal of Memory and Language, 43(1), 67-88. http://dx.doi.org/10.1006/jmla.1999.2701

Shiffrin, R.M. \& Steyvers, M. (1997). A model for recognition memory: REM—retrieving effectively from memory. Psychonomic Bulletin \& Review, 4, 145-166. http:dx.doi.org/10.3758/BF03209391 
THRESHOLD RETRIEVAL IN SEMANTIC MEMORY

Snodgrass, J.G., \& Corwin, J. (1988). Pragmatics of measuring recognition memory: Applications to dementia and amnesia. Journal of Experimental Psychology: General, 117(1), 34-50. http://dx.doi.org/10.1037/0096-3445.117.1.34

Suddendorf, T., \& Corballis, M.C. (1997). Mental time travel and the evolution of the human mind. Genetic, social, and general psychology monographs, 123(2), 133-167.

Tulving, E. (1985). Memory and consciousness. Canadian Psychology/Psychologie Canadienne, 26(1), 1-12. http://dx.doi.org/10.1037/h0080017

Vilberg, K.L. \& Rugg, M.D. (2008). Memory retrieval and the parietal cortex: a review of evidence from a dual-process perspective. Neuropsychologia, 46, 1787-99. http://dx.doi.org/10.1016/j.neuropsychologia.2008.01.004

Waidergoren, S., Segalowicz, J. \& Gilboa, A. (2012). Semantic memory recognition is supported by intrinsic recollection-like processes: "The butcher on the bus" revisited. Neuropsychologia, 50, 3573-3587.

http://dx.doi.org/10.1016/j.neuropsychologia.2012.09.040

Wixted, J.T. (2007). Dual-process theory and signal-detection theory of recognition memory. Psychological Review, 114, 152-176. http://dx.doi.org/10.1037/0033-295X.114.1.152

Yonelinas, A.P. (1994). Receiver-operating characteristics in recognition memory: evidence for a dual-process model. Journal of Experimental Psychology: Learning, Memory, and Cognition, 20(6), 1341-1354. http://dx.doi.org/10.1037/0278-7393.20.6.1341

Yonelinas, A.P. (2001). Components of episodic memory: The contribution of recollection and familiarity. The Philosophical Transactions of the Royal Society of London Series B, 356(1413), 1363-1374. http://dx.doi.org/10.1098/rstb.2001.0939

Yonelinas, A.P. (2002). The nature of recollection and familiarity: A review of 30 years of research. Journal of memory and language, 46(3), 441-517. http://dx.doi.org/10.1006/jmla.2002.2864

Yonelinas, A.P., Aly, M., Wang, W., \& Koen, J.D. (2010). Recollection and familiarity: examining controversial assumptions and new directions. Hippocampus, 20(11), 11781194. http://dx.doi.org/10.1002/hipo.20864 


\section{THRESHOLD RETRIEVAL IN SEMANTIC MEMORY}

Yonelinas, A.P., Dobbins, I., Szymanski, M.D., Dhaliwal, H.S., \& King, L. (1996). Signaldetection, threshold, and dual-process models of recognition memory: ROCs and conscious recollection. Consciousness and cognition, 5(4), 418-441.

http://dx.doi.org/10.1006/ccog.1996.0026

Yonelinas, A.P., Kroll, N.E., Dobbins, I., Lazzara, M., \& Knight, R.T. (1998). Recollection and familiarity deficits in amnesia: convergence of remember-know, process dissociation, and receiver operating characteristic data. Neuropsychology, 12(3), 323-339.

http://dx.doi.org/10.1037/0894-4105.12.3.323 
THRESHOLD RETRIEVAL IN SEMANTIC MEMORY

\section{TABLES WITH CAPTIONS}

Table 1: Experiment 1 model parameters and fit statistics for the competing signal detection models

\begin{tabular}{lrrrr}
\hline Dataset, Model & \multicolumn{3}{c}{ Model parameters } & Fit statistic \\
& $d^{\prime}$ & $\sigma$ & $R$ & $L L$ \\
\hline
\end{tabular}

\section{Experiment 1}

Full ( $n=502$, data from 500 question items)

\begin{tabular}{|c|c|c|c|c|}
\hline UEV & $\begin{array}{c}1.98 \\
{[0.76,3.22]}\end{array}$ & $\begin{array}{c}1.59 \\
{[0.55,2.63]}\end{array}$ & - & $\begin{array}{c}-80.52 \\
{[-81.62,-79.41]}\end{array}$ \\
\hline DP & $\begin{array}{c}1.01 \\
{[0.96,1.05]}\end{array}$ & - & $\begin{array}{c}.213 \\
{[.197, .229]}\end{array}$ & $\begin{array}{c}-80.41 \\
{[-81.51,-79.31]}\end{array}$ \\
\hline DP-RR & $\begin{array}{c}0.43 \\
{[0.38,0.49]}\end{array}$ & - & $\begin{array}{c}0.278 \\
{[0.264,0.292]}\end{array}$ & $\begin{array}{c}-79.69 \\
{[-80.78,-78.59]}\end{array}$ \\
\hline
\end{tabular}

Question-selective ( $n=500$, data from 411 question items)

\begin{tabular}{|c|c|c|c|c|}
\hline UEV & $\begin{array}{c}1.04 \\
{[0.99,1.09]}\end{array}$ & $\begin{array}{c}1.06 \\
{[1.03,1.10]}\end{array}$ & - & $\begin{array}{c}-68.44 \\
{[-69.46,-67.42]}\end{array}$ \\
\hline DP & $\begin{array}{c}0.75 \\
{[0.71,0.79]}\end{array}$ & - & $\begin{array}{c}0.16 \\
{[0.15,0.18]}\end{array}$ & $\begin{array}{c}-68.40 \\
{[-69.41,-67.39]}\end{array}$ \\
\hline DP-RR & $\begin{array}{c}0.33 \\
{[0.27,0.38]}\end{array}$ & - & $\begin{array}{c}0.20 \\
{[0.19,0.21]}\end{array}$ & $\begin{array}{c}-67.90 \\
{[-68.92,-66.90]}\end{array}$ \\
\hline
\end{tabular}

Note: Means are shown above 95\% Confidence Intervals in brackets. LL represent log likelihood parameters summarising each model's goodness of fit. A higher $L L$ value indicates a better model fit. 
THRESHOLD RETRIEVAL IN SEMANTIC MEMORY

Table 2: Experiment 2 model parameters and fit statistics for the competing signal detection models within full and sensitivity-matched samples

\begin{tabular}{|c|c|c|c|c|}
\hline \multirow[t]{2}{*}{ Dataset, Model } & \multicolumn{3}{|c|}{ Model parameters } & \multirow{2}{*}{$\begin{array}{c}\text { Fit statistic } \\
\qquad L\end{array}$} \\
\hline & $d^{\prime}$ & $\boldsymbol{\sigma}$ & $\boldsymbol{R}$ & \\
\hline \multicolumn{5}{|c|}{ Experiment 2 Full Samples } \\
\hline \multicolumn{5}{|c|}{ Semantic $\left(n=309, \mathrm{EV} d^{\prime}=0.85[0.80,0.91]\right)$} \\
\hline UEV & $\begin{array}{c}0.89 \\
{[0.83,0.96]}\end{array}$ & $\begin{array}{c}1.07 \\
{[1.03,1.12]}\end{array}$ & - & $\begin{array}{c}-67.59 \\
{[-68.93,-66.25]}\end{array}$ \\
\hline DP & $\begin{array}{c}0.63 \\
{[0.58,0.69]}\end{array}$ & - & $\begin{array}{c}0.14 \\
{[0.13,0.16]}\end{array}$ & $\begin{array}{c}-67.52 \\
{[-68.85,-66.18]}\end{array}$ \\
\hline DP-RR & $\begin{array}{c}0.33 \\
{[0.26,0.39]}\end{array}$ & - & $\begin{array}{c}0.15 \\
{[0.14,0.17]}\end{array}$ & $\begin{array}{c}-67.13 \\
{[-68.45,-65.81]}\end{array}$ \\
\hline \multicolumn{5}{|c|}{ Episodic $\left(n=280\right.$, EV $\left.d^{\prime}=2.02[1.91,2.12]\right)$} \\
\hline UEV & $\begin{array}{c}2.44 \\
{[2.25,2.62]}\end{array}$ & $\begin{array}{c}1.37 \\
{[1.28,1.46]}\end{array}$ & - & $\begin{array}{c}-107.41 \\
{[-110.70,-104.13]}\end{array}$ \\
\hline DP & $\begin{array}{c}1.65 \\
{[1.54,1.76]}\end{array}$ & - & $\begin{array}{c}.307 \\
{[.275, .339]}\end{array}$ & $\begin{array}{c}-107.71 \\
{[-110.97,-104.45]}\end{array}$ \\
\hline DP-RR & $\begin{array}{c}1.43 \\
{[1.29,1.56]}\end{array}$ & - & $\begin{array}{c}.221 \\
{[.190, .252]}\end{array}$ & $\begin{array}{c}-107.89 \\
{[-111.18,-104.61]}\end{array}$ \\
\hline
\end{tabular}

Experiment 2 Sensitivity-matched subsamples

Semantic $\left(n=116, \mathrm{EV} d^{\prime}=1.35[1.30,1.40]\right)$

\begin{tabular}{|c|c|c|c|c|}
\hline UEV & $\begin{array}{c}1.33 \\
{[1.23,1.45]}\end{array}$ & $\begin{array}{c}0.98 \\
{[0.89,1.08]}\end{array}$ & - & $\begin{array}{c}-66.18 \\
{[-68.09,-64.27]}\end{array}$ \\
\hline DP & $\begin{array}{c}1.11 \\
{[1.04,1.17]}\end{array}$ & - & $\begin{array}{c}.156 \\
{[.122, .190]}\end{array}$ & $\begin{array}{c}-66.33 \\
{[-68.24,-64.42]}\end{array}$ \\
\hline P-RR & $\begin{array}{c}0.70 \\
{[0.59,0.82]}\end{array}$ & - & $\begin{array}{c}.207 \\
{[.177, .585]}\end{array}$ & $\begin{array}{c}-65.93 \\
{[-67.81,-64.05]}\end{array}$ \\
\hline
\end{tabular}

Episodic $\left(n=115\right.$, EV $\left.d^{\prime}=1.32[1.14,1.50]\right)$

$\begin{array}{ccccc}\text { UEV } & 1.41 & 1.22 & & -123.96 \\ & {[1.17,1.64]} & {[1.15,1.30]} & - & {[-128.67,-119.27]} \\ \text { DP } & 1.06 & & .219 & -124.20 \\ & {[0.86,1.26]} & - & {[.180, .257]} & {[-128.75,-119.65]}\end{array}$

\begin{tabular}{|c|c|}
\hline DP-RR & $\begin{array}{c}0.80 \\
{[0.60,1.00]}\end{array}$ \\
\hline
\end{tabular}

Note: Means are shown above 95\% Confidence Intervals in brackets. EV $d^{\prime}$ represents the equal variance signal detection sensitivity parameter (see Footnote 1). A higher $L L$ value indicates a better model fit. 
THRESHOLD RETRIEVAL IN SEMANTIC MEMORY

Table 3: Correlations (Pearson's $r$ ) between Basic Descriptives for Episodic and Semantic Tasks in Experiment 2

\begin{tabular}{|c|c|c|c|c|c|c|c|c|}
\hline \multirow[t]{2}{*}{ Task } & \multicolumn{3}{|c|}{ Episodic } & \multicolumn{3}{|c|}{ Semantic } & \multirow[b]{2}{*}{$H$ conf. } & \multirow[b]{2}{*}{$C R$ conf. } \\
\hline & Parameter & EV c & $H$ conf. & CR conf. & $E V d^{\prime}$ & EV c & & \\
\hline \multirow[t]{4}{*}{ Episodic } & EV d' & $\begin{array}{c}.163^{* *} \\
{[.042, .272]}\end{array}$ & $\begin{array}{c}.406^{* * *} \\
{[.245, .546]}\end{array}$ & $\begin{array}{c}.405^{* * *} \\
{[.252, .533]}\end{array}$ & $\begin{array}{c}.081 \\
{[-.010, .168]}\end{array}$ & $\begin{array}{c}-.083 \\
{[-.176, .013]}\end{array}$ & $\begin{array}{c}-.003 \\
{[-.106, .102]}\end{array}$ & $\begin{array}{c}.043 \\
{[-.064, .156]}\end{array}$ \\
\hline & EV c & - & $\begin{array}{c}-.192^{* *} \\
{[-.307,-.069]}\end{array}$ & $\begin{array}{c}.159^{* *} \\
{[.040, .267]}\end{array}$ & $\begin{array}{c}.108 \\
{[.002, .209]}\end{array}$ & $\begin{array}{c}.098 \\
{[-.017, .213]}\end{array}$ & $\begin{array}{c}.005 \\
{[-.097, .103]}\end{array}$ & $\begin{array}{c}-.007 \\
{[-.118, .096]}\end{array}$ \\
\hline & $H$ conf. & - & - & $\begin{array}{c}.685^{* * *} \\
{[.616, .746]}\end{array}$ & $\begin{array}{c}-.140^{*} \\
{[-.251,-.033]}\end{array}$ & $\begin{array}{c}-.096 \\
{[-.219, .031]}\end{array}$ & $\begin{array}{c}.158^{\star *} \\
{[.046, .262]}\end{array}$ & $\begin{array}{c}.216^{* * *} \\
{[.111, .320]}\end{array}$ \\
\hline & CR conf. & - & - & - & $\begin{array}{c}-.132^{*} \\
{[-.233,-.030]}\end{array}$ & $\begin{array}{c}-.094 \\
{[-.211, .028]}\end{array}$ & $\begin{array}{c}.159^{\star *} \\
{[.050, .267]}\end{array}$ & $\begin{array}{c}.192^{* * *} \\
{[.084, .299]}\end{array}$ \\
\hline \multirow[t]{3}{*}{ Semantic } & EV d' & - & - & - & - & $\begin{array}{c}.092 \\
{[-.027, .210]}\end{array}$ & $\begin{array}{c}.201^{* * *} \\
{[.082, .316]}\end{array}$ & $\begin{array}{c}.221^{* * *} \\
{[.110, .145]}\end{array}$ \\
\hline & EV c & - & - & - & - & - & $\begin{array}{c}.061 \\
{[-.067, .185]}\end{array}$ & $\begin{array}{c}.021 \\
{[-.100, .145]}\end{array}$ \\
\hline & $H$ conf. & - & - & - & - & - & - & $\begin{array}{c}.555^{\star * *} \\
{[.457, .640]}\end{array}$ \\
\hline
\end{tabular}

Note: Pearson's correlation coefficients are shown above 95\% Confidence Intervals in brackets (based on 10000 bootstrapping samples). All $n s=316 . E V d^{\prime}$ and EV $c$ represents the equal variance signal detection sensitivity and bias parameters (see Footnote 1$) . H$ conf. and $C R$ conf. represent the confidence (from 1-guess, to 3 -sure) to hits and correct rejections. ${ }^{* * *}$ denotes correlation significant at the .001 level, ${ }^{* *}$ at the .01 level and ${ }^{*}$ at the .05 level. Shaded cells denote correlations for which we made specific predictions. All predictions were supported. 
THRESHOLD RETRIEVAL IN SEMANTIC MEMORY

\section{FIGURE TITLES AND CAPTIONS}

\section{Figure 1: Hypothetical ROCs from three competing signal detection models}

Across all models, $d$ ' is held constant at 1 . The left-hand-side of panels shows ROCs, the right-hand-side shows zROCs. Panel A: The unequal variance (UEV) signal detection model shows the effect of increasing $\sigma$ (lighter to darker lines) on ROC curve asymmetry about the diagonal $y=1-x$ (the dotted line that extends from $[0,1]$ to $[1,0])$. This manifests as an alteration to the gradient and intercept of the $z R O C$ lines. Panel B: The dual process (DP) signal detection model shows the effects of increasing $R$ on ROC curve asymmetry via alteration in the y axis intercept. This manifests as an increasing curve in the lower aspect of the $z R O C$ line. Panel C: the dual process recollect-to-reject (DP-RR) signal detection model shows the effects of increasing $R$ on both ROC intercepts, with no change in curve symmetry. This manifests as an introduction of two curves, in the lower and upper aspects of the $z R O C$.

Figure 2: Experiment 1 observed data and mean fits from competing signal detection models.

The left-hand-side of panels shows ROCs, the right-hand-side shows zROCs. The five points (shown at the intersection of their respective $95 \%$ Cls on the ROC plots) represent the mean observed ROC points. The three lines are constructed using the mean parameters recovered when participants are fit individually, with the UEV model shown as a dotted line, the DP model shown as a dashed line and the DP-RR model shown as a solid line. Panel A shows data and fits from the full dataset. Panel B shows data and fits from the questionselective subset.

\section{Figure 3: Experiment 1 misfit scatter plots}

Scatterplots showing target and lure discrepancies between the predicted and observed criterion points. The criterion points C1-C5 are the boundaries between "sure true"/"probably true" (C1) through to "probably false"/“sure false" (C5). The first three columns show misfit 
THRESHOLD RETRIEVAL IN SEMANTIC MEMORY

for each participant within the DP-RR (black points), DP (yellow points), and UEV (blue points) signal detection models. The 'mean' column plots the average misfit from each model simultaneously (error bars represent $95 \% \mathrm{Cls}$ ), using the same colour coding. Target and lure discrepancy are in $d^{\prime}$ units.

\section{Figure 4: Experiment 1 absolute misfit}

The mean Euclidean distance between predicted and observed criterion points for the three competing signal detection models. The criterion points $\mathrm{C} 1-\mathrm{C} 5$ are the boundaries between "sure true"/"probably true" (C1) through to "probably false"/“sure false" (C5). Error bars represent $95 \%$ Cls. Misfit distance is in $d^{\prime}$ units.

\section{Figure 5: Experiment 2 observed data and mean fits to semantic and episodic data} from competing signal detection models.

The five points at the intersections of their $95 \%$ Cls represent the means observed ROC points. The lines are constructed using the mean parameters recovered for the UEV, DP and DP-RR signal detection models. Panel A shows fits to the full sample of participants. Panel B shows fits to the sensitivity-matched subsamples. The left-hand-side of panels shows semantic data fits, the right-hand-side shows episodic data fits.

\section{Figure 6: Experiment 2 semantic data misfit scatter plots}

Scatterplots showing target and lure discrepancies between the predicted and observed criterion points for semantic data from Experiment 2. Scatter plots vary according to criterion point (C1-C5; vertical axis) and model (horizontal axis). The 'mean' column plots the average misfit from each model simultaneously (error bars represent 95\% Cls), using the same colour coding. Target and lure discrepancy are in $d^{\prime}$ units.

\section{Figure 7: Experiment 2 episodic data misfit scatter plots}


THRESHOLD RETRIEVAL IN SEMANTIC MEMORY

Scatterplots showing target and lure discrepancies between the predicted and observed criterion points for episodic data from Experiment 2. Scatter plots vary according to criterion point (C1-C5; vertical axis) and model (horizontal axis). The 'mean' column plots the average misfit from each model simultaneously (error bars represent 95\% Cls), using the same colour coding. Target and lure discrepancy are in $d^{\prime}$ units.

\section{Figure 8: Experiment 2 absolute misfit to semantic and episodic data}

The mean Euclidean distance between predicted and observed criterion points for the three competing signal detection models. Panel A shows mean absolute misfit for semantic data and Panel B for episodic data. Error bars represent 95\% Cls. Misfit distance is in $d^{\prime}$ units.

Figure 9: Within-Subjects Semantic and Episodic $R$ parameters.

Semantic task $R$ parameters were recovered using the DP-RR model, episodic $R$ parameters using the DP model. 

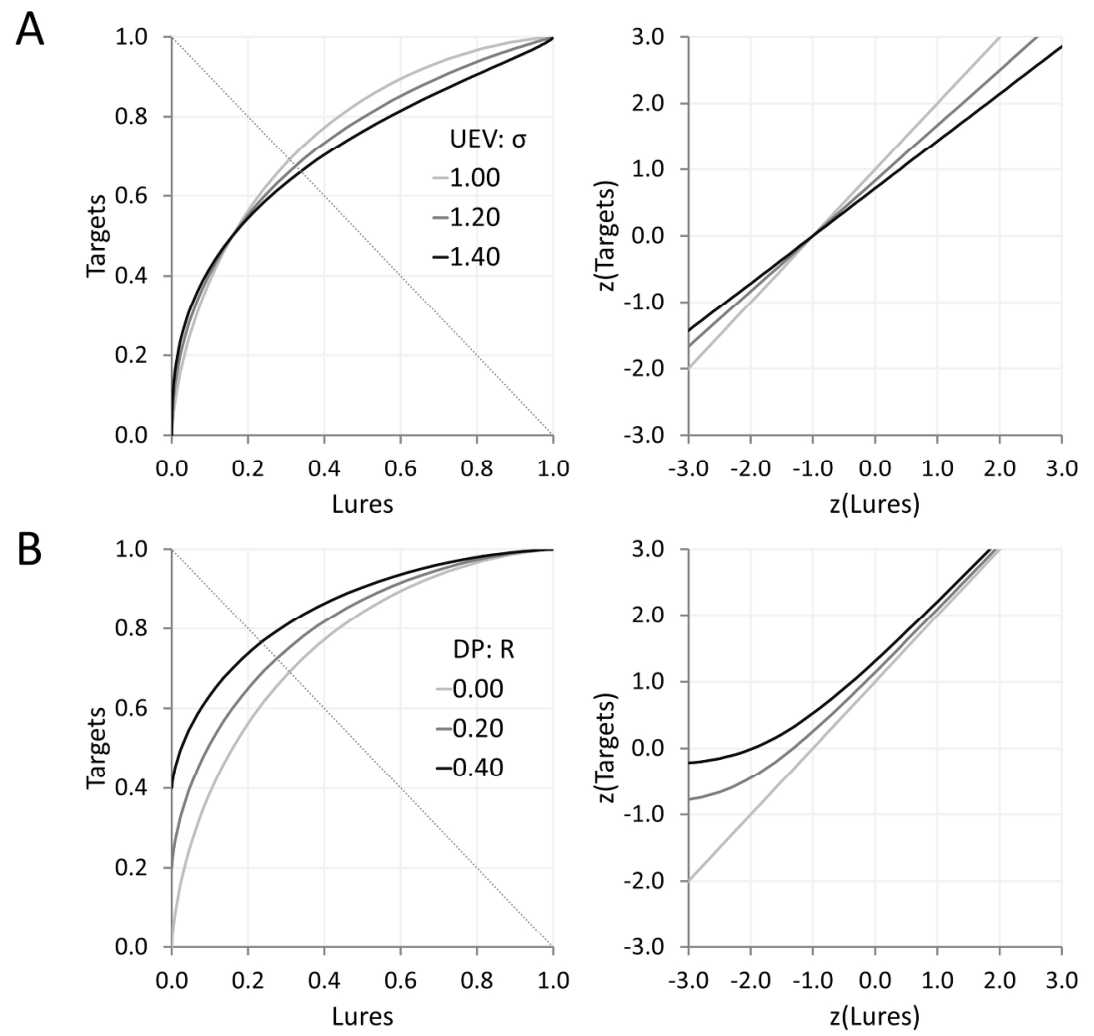

C
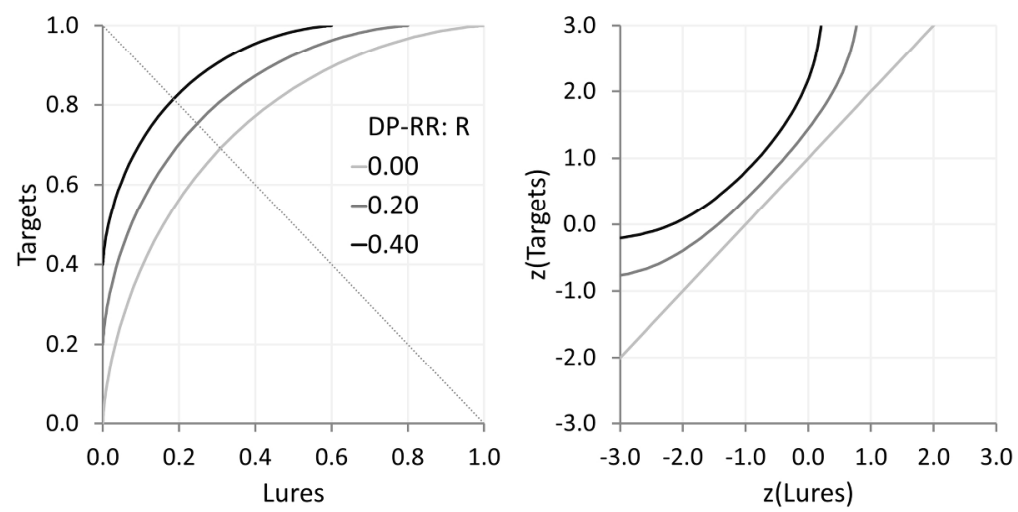

Figure 1: Hypothetical ROCs from three competing signal detection models

Across all models, $d^{\prime}$ is held constant at 1 . The left-hand-side of panels shows ROCs, the right-hand-side shows zROCs. Panel A: The unequal variance (UEV) signal detection model shows the effect of increasing $\sigma$ (lighter to darker lines) on ROC curve asymmetry about the diagonal $\mathrm{y}=1-\mathrm{x}$ (the dotted line that extends from $[0,1]$ to $[1,0])$. This manifests as an alteration to the gradient and intercept of the zROC lines. Panel $B$ : The dual process (DP) signal detection model shows the effects of increasing R on ROC curve asymmetry via alteration in the $y$ axis intercept. This manifests as an increasing curve in the lower aspect of the zROC line. Panel C: the dual process recollect-to-reject (DP-RR) signal detection model shows the effects of increasing $\mathrm{R}$ on both ROC intercepts, with no change in curve symmetry. This manifests as an introduction of two curves, in the lower and upper aspects of the zROC. $190 \times 267 \mathrm{~mm}(300 \times 300 \mathrm{DPI})$ 
A ...... UEV - - DP —DP-RR

Figure 2: Experiment 1 observed data and mean fits from competing signal detection models. The left-hand-side of panels shows ROCs, the right-hand-side shows zROCs. The five points (shown at the intersection of their respective $95 \%$ CIs on the ROC plots) represent the mean observed ROC points. The three lines are constructed using the mean parameters recovered when participants are fit individually, with the UEV model shown as a dotted line, the DP model shown as a dashed line and the DP-RR model shown as a solid line. Panel A shows data and fits from the full dataset. Panel B shows data and fits from the questionselective subset. $218 \times 212 \mathrm{~mm}(220 \times 220 \mathrm{DPI})$ 
Figure 3: Experiment 1 misfit scatter plots

Scatterplots showing target and lure discrepancies between the predicted and observed criterion points. The criterion points $\mathrm{C} 1-\mathrm{C} 5$ are the boundaries between "sure true"/"probably true" (C1) through to "probably false"/"sure false" (C5). The first three columns show misfit for each participant within the DP-RR (black points), DP (yellow points), and UEV (blue points) signal detection models. The 'mean' column plots the average misfit from each model simultaneously (error bars represent 95\% CIs), using the same colour coding. Target and lure discrepancy are in d' units. $250 \times 297 \mathrm{~mm}(300 \times 300 \mathrm{DPI})$ 


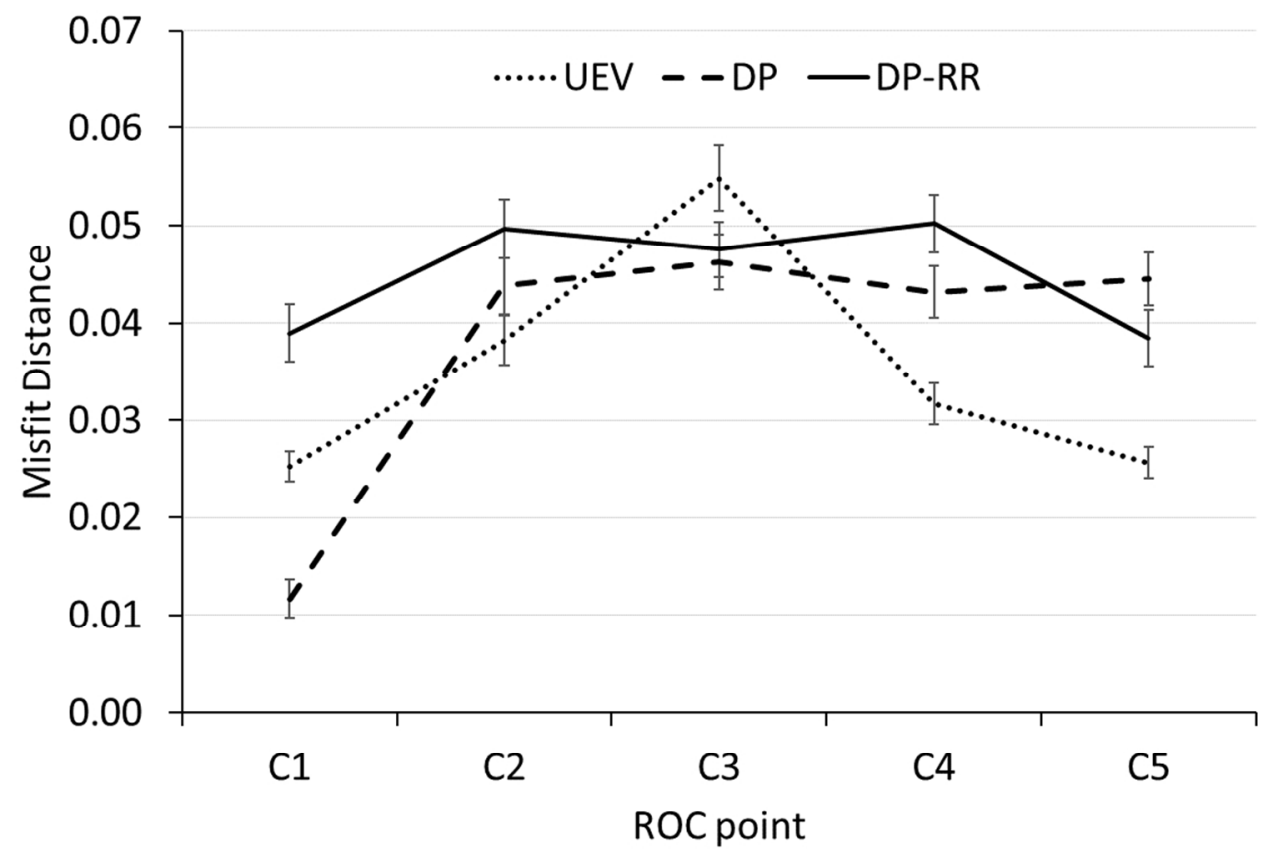

Figure 4: Experiment 1 absolute misfit

The mean Euclidean distance between predicted and observed criterion points for the three competing signal detection models. The criterion points C1-C5 are the boundaries between "sure true"/"probably true" (C1) through to "probably false"/"sure false" (C5). Error bars represent 95\% CIs. Misfit distance is in d' units. $408 \times 277 \mathrm{~mm}$ (72 x 72 DPI) 
A
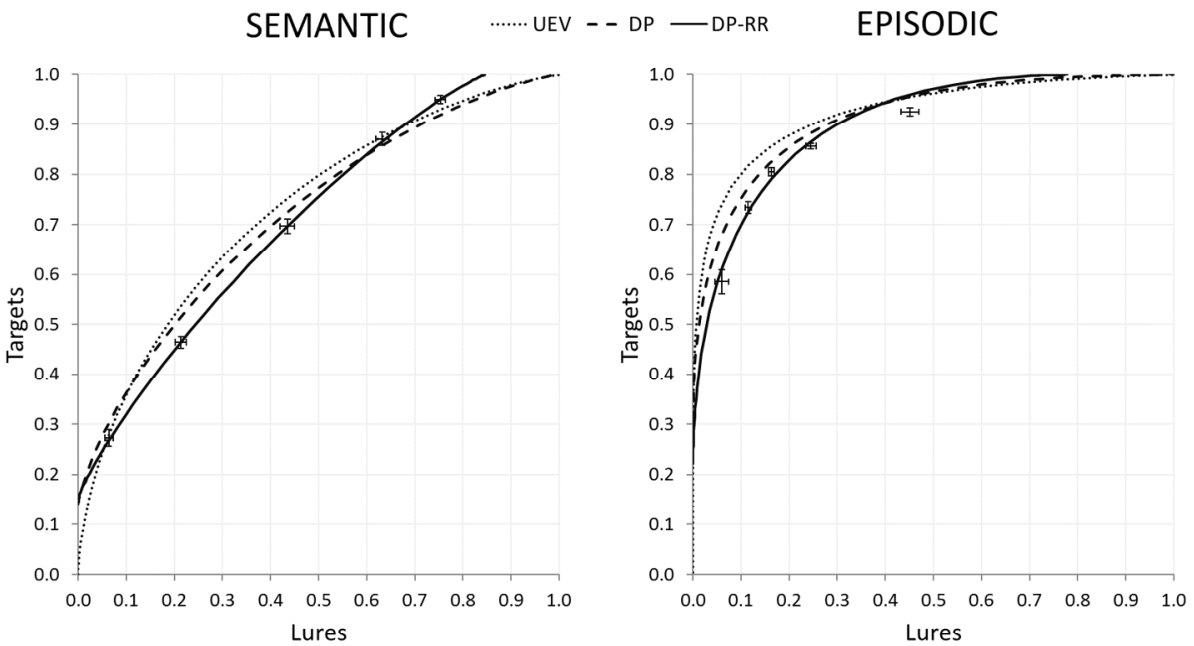

B

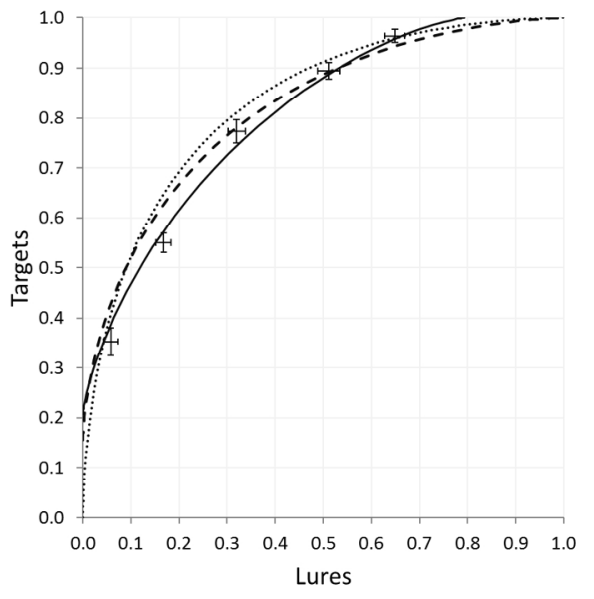

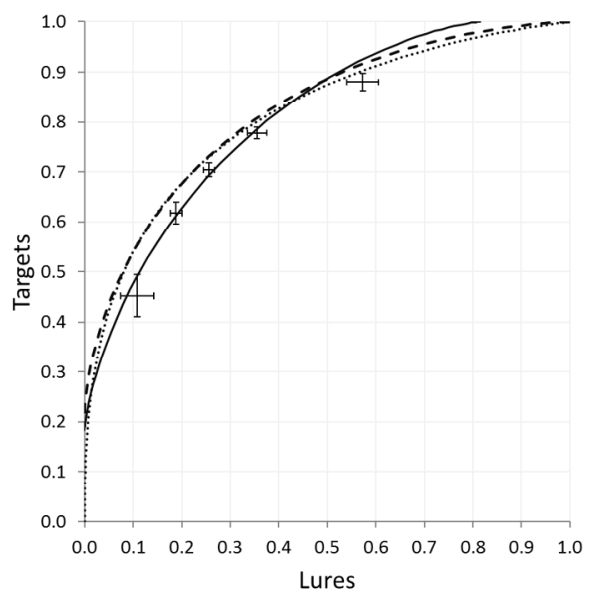

Figure 5: Experiment 2 observed data and mean fits to semantic and episodic data from competing signal detection models.

The five points at the intersections of their 95\% CIs represent the means observed ROC points. The lines are constructed using the mean parameters recovered for the UEV, DP and DP-RR signal detection models.

Panel A shows fits to the full sample of participants. Panel B shows fits to the sensitivity-matched subsamples. The left-hand-side of panels shows semantic data fits, the right-hand-side shows episodic data fits.

$218 \times 212 \mathrm{~mm}(220 \times 220 \mathrm{DPI})$ 


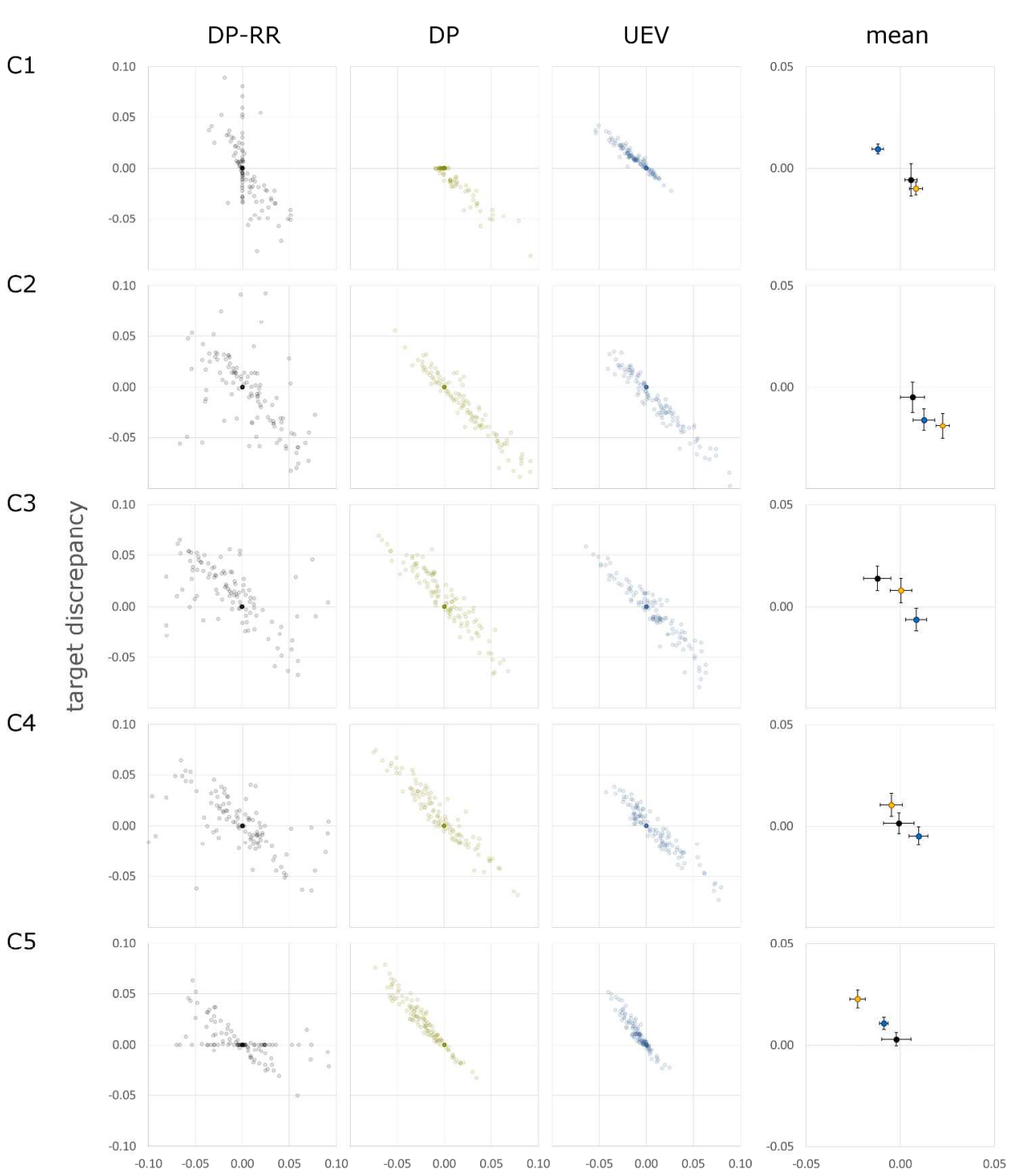

lure discrepancy

Figure 6: Experiment 2 semantic data misfit scatter plots Scatterplots showing target and lure discrepancies between the predicted and observed criterion points for semantic data from Experiment 2 . Scatter plots vary according to criterion point (C1-C5; vertical axis) and model (horizontal axis). The 'mean' column plots the average misfit from each model simultaneously (error bars represent $95 \%$ CIs), using the same colour coding. Target and lure discrepancy are in d' units. $250 \times 297 \mathrm{~mm}(300 \times 300$ DPI) 
Figure 7: Experiment 2 episodic data misfit scatter plots Scatterplots showing target and lure discrepancies between the predicted and observed criterion points for episodic data from Experiment 2. Scatter plots vary according to criterion point (C1-C5; vertical axis) and model (horizontal axis). The 'mean' column plots the average misfit from each model simultaneously (error bars represent $95 \%$ CIs), using the same colour coding. Target and lure discrepancy are in d' units. $250 \times 297 \mathrm{~mm}(300 \times 300$ DPI) 
A

\section{Semantic}

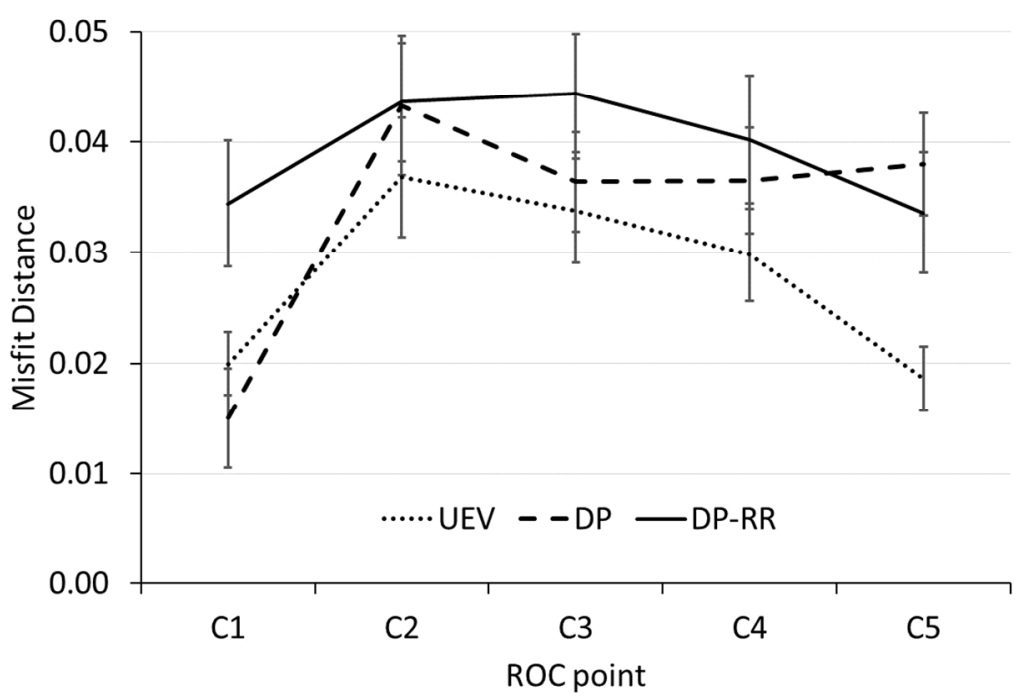

B

\section{Episodic}

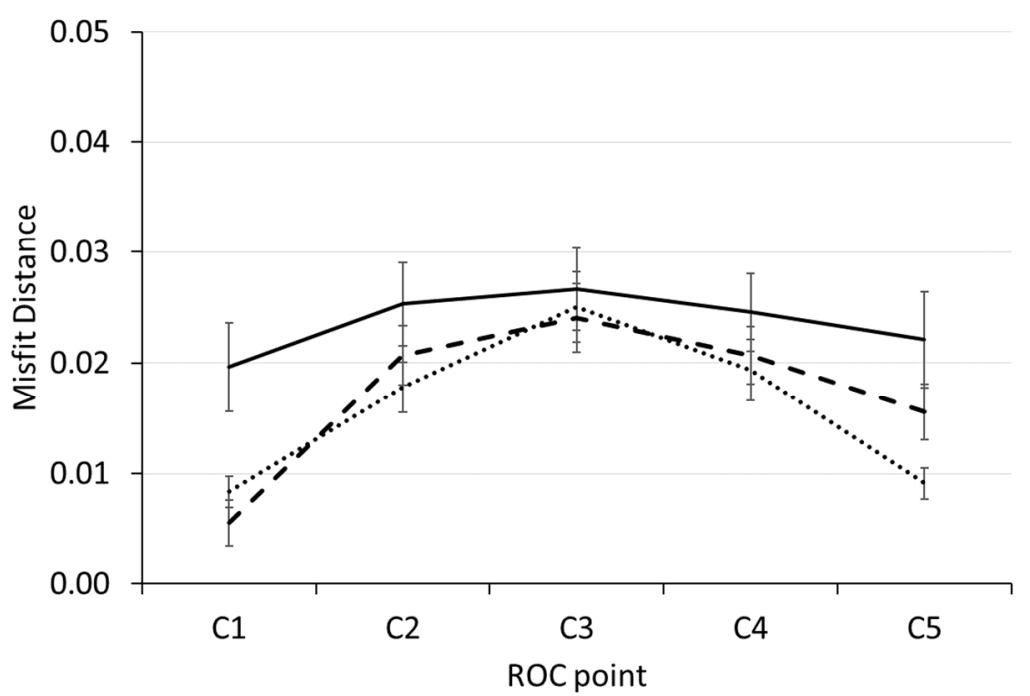

Figure 8: Experiment 2 absolute misfit to semantic and episodic data

The mean Euclidean distance between predicted and observed criterion points for the three competing signal detection models. Panel A shows mean absolute misfit for semantic data and Panel B for episodic data. Error bars represent $95 \%$ CIs. Misfit distance is in d' units. $135 \times 198 \mathrm{~mm}(220 \times 220$ DPI $)$ 


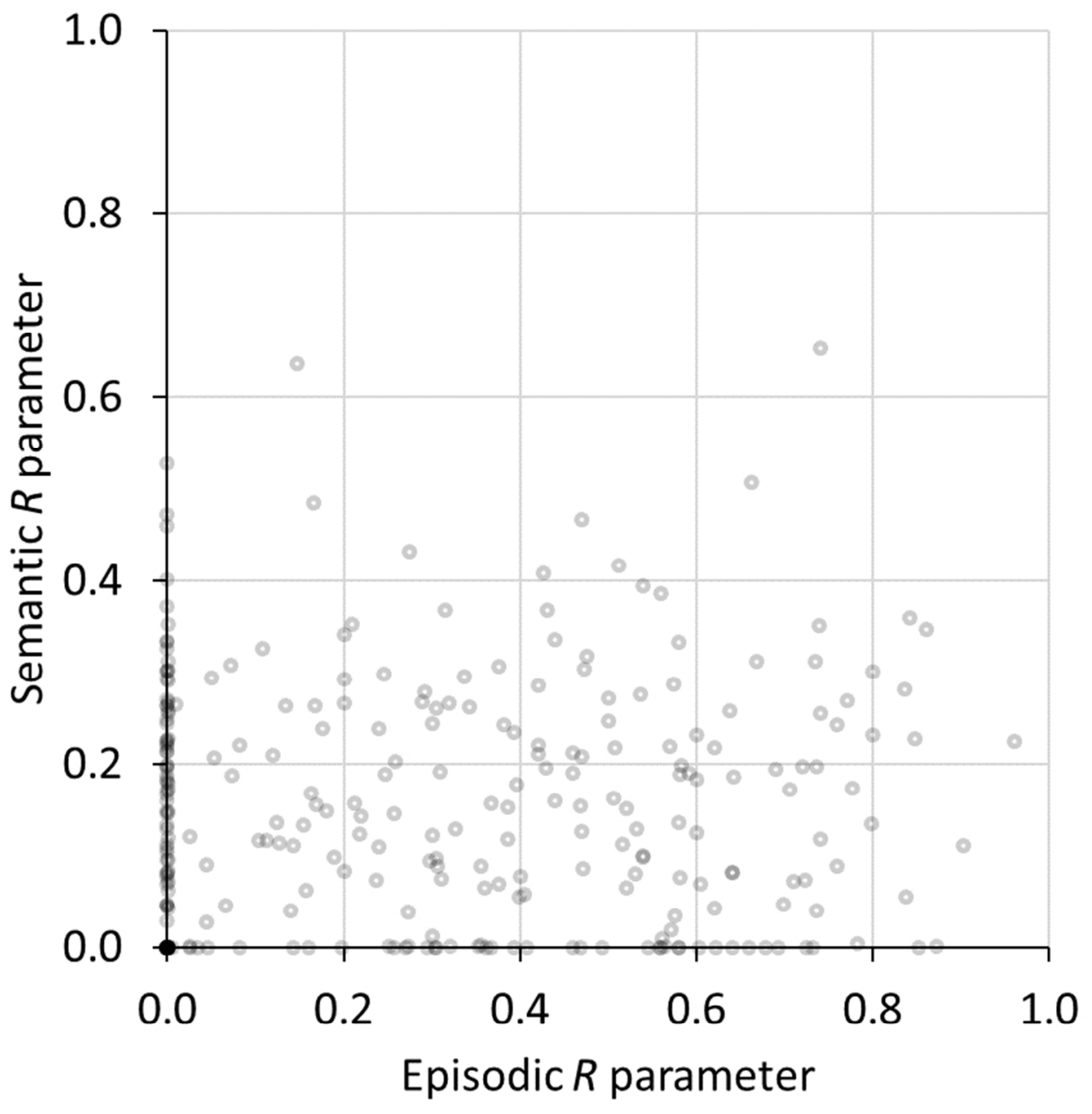

Figure 9: Within-Subjects Semantic and Episodic R parameters. Semantic task $R$ parameters were recovered using the DP-RR model, episodic R parameters using the DP model.

$316 \times 317 \mathrm{~mm}(72 \times 72 \mathrm{DPI})$ 
Supplementary Materials A: Semantic Recognition Memory Questions

\begin{tabular}{|c|c|c|c|c|}
\hline \# & Question & Target & Lure & Exc. \\
\hline 1 & Who won a record 8 Grammy Awards in 1984? & Michael Jackson & Bryan Adams & \\
\hline 2 & Pan Troglodyte is the Latin name for which creature? & Chimpanzee & Gorilla & \\
\hline 3 & Which US state has the nickname 'The Natural State'? & Arkansas & Washington & \\
\hline 4 & What is Luke Skywalker's uncle's name? & Owen & Ben & \\
\hline 5 & $\begin{array}{l}\text { The cricketer, Mudhsuden Singh Panesar, goes by which } \\
\text { nickname? }\end{array}$ & Monty & Spinner & \\
\hline 6 & What nationality is film director Baz Luhrmann? & Australian & Canadian & \\
\hline 7 & Who wrote the Harry Potter series of books? & J.K. Rowling & J.R.R. Tolkien & $\mathrm{x}$ \\
\hline 8 & What is the common name for the compound $\mathrm{C} 6 \mathrm{H} 12 \mathrm{O}$ ? & Glucose & Kerosene & \\
\hline 9 & Port-au-Prince is the capital of which country? & Haiti & Morocco & \\
\hline 10 & When did Bill Clinton first become president of the US? & 1993 & 1990 & \\
\hline 11 & James Bond first drove an Aston Martin which film? & Goldfinger & Octopussy & \\
\hline 12 & $\begin{array}{l}\text { What is the first name of English footballer Wayne } \\
\text { Rooney's wife? }\end{array}$ & Coleen & Victoria & \\
\hline 13 & What is the common name of Sodium Borate? & Borax & Table Salt & \\
\hline 14 & Who has the nickname The Austrian Oak? & $\begin{array}{l}\text { Arnold } \\
\text { Schwarzenegger }\end{array}$ & Christoph Waltz & \\
\hline 15 & When did Euro coins and banknotes enter circulation? & 2002 & 1998 & \\
\hline 16 & Antibiotics were first produced from what? & Fungi & Sand & \\
\hline 17 & $\begin{array}{l}\text { Which Swedish car manufacturer started as aeroplane } \\
\text { company? }\end{array}$ & SAAB & Volvo & \\
\hline 18 & What nationality was the painter Gustav Klimt? & Austrian & German & \\
\hline 19 & $\begin{array}{l}\text { Who shouts "You shall not pass" in the film The } \\
\text { Fellowship of the Ring? }\end{array}$ & Gandalf & Frodo Baggins & $\mathrm{x}$ \\
\hline 20 & Who sailed from Bristol to North America in 1497? & John Cabot & $\begin{array}{l}\text { Christopher } \\
\text { Columbus }\end{array}$ & \\
\hline 21 & Where were the 2008 Summer Olympics held? & Beijing & Sydney & $\mathrm{x}$ \\
\hline 22 & In what film was there a character called Tyler Durden? & Fight Club & American Beauty & $x$ \\
\hline 23 & Prospero and Miranda are characters in which play? & The Tempest & $\begin{array}{l}\text { A Midsummer } \\
\text { Night's Dream }\end{array}$ & \\
\hline 24 & Who wrote the novel 'The Catcher in the Rye'? & J.D. Salinger & Truman Capote & \\
\hline 25 & Where is the headquarters of the European Central Bank? & Frankfurt & Strasbourg & \\
\hline 26 & $\begin{array}{l}\text { According to the UNWTO (2012) rankings, which country } \\
\text { is the most popular tourist destination? }\end{array}$ & France & Great Britain & \\
\hline 27 & $\begin{array}{l}\text { In which year did Casablanca win an Oscar for best } \\
\text { picture? }\end{array}$ & 1944 & 1946 & \\
\hline 28 & $\begin{array}{l}\text { Laughing gas is a compound of oxygen and which other } \\
\text { gas? }\end{array}$ & Nitrogen & Helium & \\
\hline 29 & What was America's first National Park? & Yellowstone & Everglades & \\
\hline 30 & What is the national bird emblem of the United States? & Eagle & Owl & $x$ \\
\hline 31 & Who wrote the 'Zombie Survival Guide'? & Max Brooks & Richard Matheson & \\
\hline 32 & How many 'toes' does a camel have on each foot? & 2 & 3 & \\
\hline 33 & What is the capital of Belarus? & Minsk & Belgrade & \\
\hline 34 & How many players are there in a soccer team? & 11 & 10 & \\
\hline 35 & Where was the actor Will Smith born? & Philadelphia & Miami & $\mathrm{x}$ \\
\hline
\end{tabular}


Who directed the movie This is Spinal Tap?

Who said "Freedom is indivisible, and when one man is enslaved, all are not free"?

How many national parks are there in the United

Kingdom?

How many legs does an ant have?

An early Apple computer was given which girl's name?

Who was the 40th President of the United States?

Which Finnish heavy metal music group won the Eurovision song contest in 2006?

Which sportsman's nickname was 'The Refrigerator'?

Which French footballer also stars in a Ken Loach film set in Manchester?

In Norse mythology, who is the god of thunder?

Ringo Starr replaced which drummer in The Beatles?

What is the French for 'brain'?

The Rasmus and Nightwish are both bands form which country?

What was Butch Cassidy's real name?

What was Darth Vader's name before he turned to the dark side?

Who played the lead role in the film Castaway?

Which city is the capital of Spain?

Where does the Scottish Parliament sit?

Which computer company did Steve Jobs start after leaving Apple?

Which English King was beheaded in 1649?

Which of Dickens' novels was partly set in the US?

What is the foodstuff which gave its name to the 'pantry'? How many times have humans landed on the moon?

In which year were the Manchester United football team involved in the Munich Air Crash?

Who wrote the novel 'Robinson Crusoe'?

The Concorde aircraft was a collaboration between the UK and which country?

Which newspaper was the first to carry a crossword puzzle?

From where might you browse and borrow books?

What is Avogadro's number approximately equal to?

By what process do plants produce oxygen?

The distance of a marathon race is

What is the name of the supercontinent that existed from approximately 510 to 180 million years ago?

Who invented the television?

How long does it take for the moon to orbit the Earth?

How long is the normal length of play in a game of rugby?

Who killed John Lennon?

What part of a plant is the potato an example of?
Rob Reiner
Nelson Mandela

15

6

Lisa

Ronald Reagan

Lordi

William Perry

Eric Cantona

Thor

Pete Best

Cerveau

Finland

Robert Leroy Parker

Anakin Skywalker

Tom Hanks

Madrid

Holyrood

Next

Charles I

Martin Chuzzlewit

Bread

Six

1958

Daniel Defoe

France

New York World

Library

$6.02 \mathrm{E}+23$

Photosynthesis

$26.2 \mathrm{miles}(42.2 \mathrm{~km})$

Pangea

John Logie Baird

27 days

80 minutes

Mark Chapman

Tuber
Terry Gilliam

Martin Luther King

12

4

Sara

George Bush

Axewitch

Ted Washington

Zinedine Zidane

Odin

Keith Moon

Creneau

Germany

Gerald Cassidy

Count Dooku

Kevin Costner

Barcelona

Westminster

Dell

Charles II

Little Dorrit

Bacon

Five

1966

Jonathan Swift

Germany

The Times

Theatre

$X$

1.66E-27

Respiration

X

28.8 miles $(46.4 \mathrm{~km})$

Cambria

Tim Berners-Lee

27 hours

90 minutes

Jack Ruby

Rhizome 
Which member of the Beatles married Yoko Ono?

How many states is Germany made up of?

Regina George is a character in which film?

How many hours are in a day?

When did Neil Armstrong first land on the moon?

With whom does Anna Karenina commit adultery?

Where is Michelangelo's statue David?

When is Martin Luther King Jr's Day?

If you're a bird, I'm a bird is a quote from which film?

What is the captain's name in Moby Dick?

At which pole do penguins live?

Who was the third president of the United States of America?

The Berlin Wall fell in which year?

2Pac represented which coast during the hip hop rivarly of the 1990s?

ABBA won the Eurovision Song Contest in which year? The chemical symbol Au represents what element in the periodic table?

Luna Lovegood was sorted into which house in Harry Potter?

Apart from white and red, what colour is featured in the flag of the Russian federation?

What colour do you get from mixing red and blue?

How many months in the Gregorian calendar have 31 days?

Please sir, I want some more. is a quote from which book?

What is the capital of Ghana?

Organic chemistry concerns the study of matter that contains which element?

Apple's spreadsheet package is called

Mains electricity in the USA is transmitted as what sort of current?

What Roman numeral represents the number five?

What was the first Disney feature film?

What does NASA stand for?

What is the rabbit called in Beatrix Potter's tales?

When did Gutenberg introduce the printing press?

Sushi is a delicacy from which country?

What is Sherlock Holmes' partner called?

How many rings are on the Olympic flag?

Where can you go to see old paintings?
John Lennon

16

Mean Girls

24

20th July 1969

Vronsky

Florence

the 3rd Monday of

January

The Notebook

Ahab

South Pole

Thomas Jefferson

1989

West Coast

1974

Gold

Ravenclaw

Blue

Purple

7

Oliver Twist

Accra

Carbon

Numbers

Alternating current

(AC)

$\mathrm{V}$

Snow White and The

Seven Dwarfs

National

Aeronautics and

Space Administration

Peter

1450s

Japan

Watson

5

Museum
Paul McCartney

20

John Tucker Must $\quad \mathrm{X}$

Die

25

20th August 1969

Oblonsky

Rome

the 3rd Thursday of

November

(500) Days of

Summer

Ishmael

North Pole

John Adams

1991

East Coast

1980

Silver

Hufflepuff

Green

Green

$x$

6

Huckleberry Finn

X

Abidjan

Oxygen

Calc

Direct current (DC)

$X$

$x$

Bambi

National Air and

Space Academy

James

1540s

China $\quad X$

Walton $X$

6

Zoo

$x$ $x$ 
107 Foie gras is made from what organ?

108 Which country is associated with haggis?

109 Where is Pope Francis from?

110 Which of the world's longest rivers flows through Kenya?

111 Fermat's Last Theorem is closely associated with which scientific subject?

112 An important concept in game theory, what concept helps predict outcomes when there are several decisionmakers?

113 What adjective does F. Scott Fitzgerald use in the title of a book to describe its protagonist Jay Gatsby?

114 How many letters are in the English alphabet?

115 When was the attack on Pearl Harbour?

116 In what year was Queen Elizabeth II born?

117 How many players are in a basketball team?

118 What season follows spring?

119 If written out in full, how many zeros are there in a googol?

120 Someone who will not wait happily could be described as:

121 Which member of the bear family eats only bamboo?

122 What is the introduction of material to a person's immune system to prevent disease is called?

123 In the Gregorian calendar, which month only has 28 days?

124 Practical jokes are traditionally celebrated on which day of the year?

125 What is Latin for beard?

126 What is the medical name for a belly button?

127 What is the currency of the Czech Republic?

128 Ansel Adams, Willard Van Dyke and Edward Weston founded which photographical collective?

129 How many chambers is a cow's stomach divided into?

130 Which word, encountered in computer security, literally means 'the part of a plant containing grains'?

131 What is the third letter of the English alphabet?

132 London lies on which river?

133 In which country is the city of Berlin?

134 In the Muppets, what nationality is the Chef?

135 How many legs are there on the Isle of Man flag?

136 Which of the two cities, Paris or London, lies the furthest north?

137 Which of the two actors, Bill Murray or Ben Stiller is the older?

138 Who directed 'The Life Aquatic'?

139 Morrissey was the lead singer of which Manchester band?

140 The film 'Man on the Moon' is about which American comedian?

141 What meat is traditionally used in a Shepherd's Pie?

142 In the Pixar animation, what kind of fish is 'Nemo'?

$\begin{array}{ll}\text { Liver } & \text { Heart } \\ \text { Scotland } & \text { Wales } \\ \text { Argentina } & \text { Brazil } \\ \text { Nile } & \text { Amazon } \\ \text { Mathematics } & \text { Psychology }\end{array}$

Nash Equilibrium Mensch Equilibrium

Great Grand

$26 \quad 25$

$x$

7th December 1941 7th December 1945

19261925

$5 \quad 7$

Summer Winter

$100 \quad 1000$

Impatient Attentive $\quad X$

Panda

Vaccination

Polar bear

Examination

$x$

$x$

February

1st April

April

$x$

25th December $\quad X$

Barba

Umbilicus

Bucca

Labrum

Koruna

Ruble

Group f/64

Focus Group

4

Shibboleth

2

Passcode

C

The Thames

Germany

Swedish

3

London

D

$x$

The Severn

$x$

Austria

French

2

Paris

Bill Murray

Ben Stiller

Wes Anderson

The Smiths

Michel Gondry

Joy Division

Andy Kaufman

John Belushi

Lamb

Beef

Clown Fish
Gold Fish 
143 Who served as the president of Iraq between 1979 and 2003?

144 Which mineral is often referred to as fool's gold?

145 On which continent is the country Guyana?

146 What is a plant with a trunk, branches and leaves usually referred to as?

147 Wool is most commonly derived from the coat of which animal?

148 The Wimbledon tennis tournament takes place in which English city?

149 The Americas Cup is a competition involving which mode of transport?

150 Stella Artois is a beer from which country?

151 Who wrote the book 'Charlie and the Chocolate Factory'?

152 What is the international dialling code for Brazil?

153 Which band sang 'Losing My Religion'?

154 Who starred as the cross-dressing lead in 'Tootsie'?

155 Who wrote the book 'The Corrections'?

156 Which band released the 1977 album 'Rumours'?

157 The daffodil is the national flower of which country?

158 The Guardian newspaper was founded in which English city?

159 Microsoft has headquarters in which US city?

160 What is the symbol for the chemical element potassium?

161 The onion is the most widely cultivated species in which plant genus?

162 The 1904 World's Fair took place in which city?

163 What is the boiling point of water in Fahrenheit?

164 The drug heroin can be derived from which plant?

165 In which country can the Great Pyramid of Giza be found?

166 Lego originated in which country?

167 Sake is an alcoholic drink originating in which country?

168 What term describes the fear of nakedness?

169 A 9V battery produces what sort of current?

170 Light is emitted and absorbed in packets called:

171 Who won an Oscar for their acting role in the film '12 Years A Slave'?

172 Actor Jon Hamm was made famous by his role in which US television series?

173 Who won the 2013 World Series?

174 How many days are there in a Gregorian leap year?

175 What is the past participle of 'to sit'?

176 What is the plural of 'child'?

177 How many old pence were there in a British Shilling?

178 'Dinosaur' derives from the Greek words meaning what?

179 On a clear, bright, cloudless day, what colour is the sky?

180 In the world of music, what does CD stand for?
Saddam Hussein

Osama Bin Laden

Pyrite

South America

Tree

Sheep

London

Boat

Belgium

Roald Dahl

55

R.E.M.

Dustin Hoffman

Jonathan Franzen

Fleetwood Mac

Wales

Manchester

Redmond

$\mathrm{K}$

Allium

St Louis

212

Poppy

Egypt

Denmark

Japan

Gymnophobia

DC

Photons

Lupita Noyng'o

Mad Men

Boston Red Sox

366

Sat

Children

12

Terrible lizard

Blue

Compact Disc
Bauxite

Africa

Bush

Cow

$x$

Liverpool

Car

France

Enid Blyton

54

Radiohead

Al Pacino

David Foster

Wallace

The Eagles

The Netherlands

London

Cupertino

$\mathrm{Na}$

Salvia

Chicago

232

Hemp

Turkey

Germany

China

Gynophobia

AC

Protons

Chiwitel Ejiofor

Breaking Bad

New York Yankees

367

Sitting

$x$

Childish

10

Eating beast

White

Computer Data

$x$ 
181 A dozen is a grouping of how many?

182 In what year did the micro blogging site Twitter start?

183 Stanley Kubrick is most well known for being what?

184 Who was the first man to set foot on the moon?

185 What decade is often described as 'swinging'?

186 What colour is traditionally worn to funerals?

187 In Western cultures, shaking someone's hand is usually a form of:

188 The device on which you hang your clothes to dry outside is called a:

189 When was smoking in pubs banned in the United Kingdom?

190 In what year was Justin Bieber born?

191 Someone who comes from Bristol is called what?

192 What is the process which returns water to the atmosphere from the earth's surface?

193 When fruit is ready to be picked and eaten, it is described as:

194 Great Britain is on which continent?

195 In which way would you usually turn a tap to turn it on?

196 On what side of the road should one drive in France?

197 'Jaws' was a film about what sort of animal?

198 Who is facebook's CEO?

199 Some young women were referred to as Flappers in which decade?

200 Holding one's hair back with a hair tie is referred to as a tail.

201 The members of the lowest caste in India are referred to as?

202

Who exclaims "Out, damned spot!" in the play Macbeth?

203 What reptiles complete the film title ' on a plane'?

204 In 'Game of Thrones' the Stark family's motto is?

205 Which e-book reader was designed by Amazon?

206 How many states make up the United States of America?

207 What magnitude of handicap is indicative of a good golf player?

208 What pattern consists of horizontal and vertical stripes in multiple colours?

209 How many complete novels did Jane Austen write?

210 The last German Emperor was called?

211 Who is creative director for Chanel?

212 The island of Formentera lies in which island group?

213 In music, what does the abbreviation DJ stand for?

214 Snoop Dogg released a reggae album under which alias?

215 Wine is typically made from which fruit?

216 'Zumba' describes what activity?

217 Proteins consist of chains of:
12

2006

Film Director

Neil Armstrong

1960s

Black

Greeting

Washing line

2007

1994

A Bristolian

Evaporation

Ripe

Europe

Clockwise

The right

A shark

Mark Zuckerberg

The Roaring

Twenties

Pony

The Untouchables

Lady Macbeth

Snakes

Winter is coming.

Kindle

50

Low

Tartan

6

Wilhelm II

Karl Lagerfeld

Balearic

Disc Jockey

Snoop Lion

Grapes

A dance fitness

program

Amino acids
10

2008

Painter

$x$

Buzz Aldrin

1970s

Red

Insult

$x$

$\mathrm{X}$

Drying cord

2008

1993

A Bristain

Transpiration

Rested

$x$

North America

$x$

Anti-clockwise

The left

A crocodile

$x$

Sheryl Sandberg

The Booming Fifties

Horse

The Invisibles

Macbeth

Turtles

$x$

The lark is calling.

Kobo

52

High

Polka Dots

5

Bismarck

Marc Jacobs

Canary

Dancing Jockey

X

Snoop Tiger

Oranges

$x$

A weight lifting $\quad X$

routine

Fatty acids
$X$ 
218 Who was the ancient Greek god of the underworld?

219 Which apes are more closely related to humans, bonobos or gorillas?

220 'Suzi \& the $7 D^{3}$ sseldorfs' is the name given to:

221 What does considering a task 'a piece of cake' imply about it?

222 Which university still operating today is the oldest in the world?

223 Who won the FIFA World Cup 1998?

224 In what city was 'eau de cologne' invented?

225 In which country would you be most likely to find a Kibbutz?

226 Which city is the largest in Western Asia?

227 'Bridget Jones's Diary' is based on which 19th century novel?

228 Who delivered the shortest acceptance speech at an Oscars ceremony?

229 What is the speed of light?

230 What is the Earth's gravitational field strength in $\mathrm{m} / \mathrm{s} 2$ ?

231 What is the capital of Canada?

232 Which of Goethe's works inspired a series of suicides?

233 Water makes up what percentage of a typical cucumber?

234 On what does Sleeping Beauty prick her hand before falling into a deep sleep?

235 Which city is considered the birthplace of the stock market?

236 In 'The Wind in the Willows', what hobby is Mr. Toad obsessed with?

237 What colour are the eyebrows of the Wood Grouse?

238 What is a hexameter?

239 From what event did the unification of the German language develop?

240 Which monarch is described as the Sun King?

241 What did Mr. Spock from Star Trek often call unknown but intriguing things?

242 How do the Beatles' lyrics "Ob-la-di, ob-la-da, life goes on" continue?

243 Where did Napoleon I die?

244 How does the poem with the first line "I eat my peas with" continue?

245 How are spectacle lenses for shortsighted people shaped?

246 The Supremes urge their listeners to "stop in the name of" what?

247 In 'The Adventures of Asterix', why is Obelix never allowed any magic potion?

248 In a Roman legion, what usually consisted of two
Hades

Bonobos

A nail polish

It is easily accomplished

The University of

Bologna

France

Cologne

Israel

Tehran

Pride and Prejudice

Alfred Hitchcock

$299792458 \mathrm{~m} / \mathrm{s}$

9.81

Ottawa

The Sorrows of

Young Werther

90-98\%

A Spindle

Amsterdam

Motoring

Red

A classic metre in

literature

Publication of

Martin Luther's Bible

Translation

Louis XIV

Fascinating

Bra

Saint Helena

Honey

Concave

Love

He fell into a

cauldron full of the potion as a child.

Maniples
Athene

X

Gorillas

A film

It is just one of

X

many

The University of

Oxford

Brazil

Paris

Slovenia

Baghdad

Madame Bovary

Joe Pesci

399792458 m / s

19.81

Vancouver

Faust

$50-60 \%$

A Rose

London

Betting

White

A classic measure of length

Ludwig S $S^{3}$ tterlin's

Writing Reform

Louis XVI

Interesting

La

Elba

Potatoes

Convex

Law

$\mathrm{He}$ is too

overweight.

Cohors 
centuriae?

249 In what city can the original international prototype of

Paris

By performing a waggle dance Always look on the bright side of life.

The Wizard Merlin

$D^{3}$ sseldorf

Europa

Cavern Club

A Mercedes Benz

Katharine Hepburn

Sing Sing

Donkeys

Sea of Galilee

Don Giovanni

The Organ

Spice World

Britney Spears' and Madonna's kiss

RiRi

Jacques Chirac

Flavio Briatore

Austria

1935

Adams

Unicorn

Dolce \& Gabbana

Like a Virgin

Owl

Washoe

John Forbes Nash, Jr.
London

Through a distinct buzzing Hey Babe, take a walk on the wild side.

Sir Lancelot

Perth

Aphrodite

Tavern Club

World Peace

Audrey Hepburn

The Rock

Bees

Dead Sea

The Marriage of Figaro

The Violin

Girl Power

Lady Gaga's meat

dress

$\mathrm{RiHa}$

Nicolas Sarkozy

Seal

Germany

1945

Miller

Dragon

Victor \& Rolf

Material Girl

Piglet

Koko

Richard P. Feynman 
277 In what city was Albert Einstein born?

278 When were bananas first supplied in the UK?

279 The chemical element with atomic number 110 was named after which German city?

280 What chemical compound makes many plants green?

281 How heavyáis an Ostrich's egg?

282 How many national flags have ten or more colours?

283 Frankly, my dear, I don't give a damn is a line from which film?

284 In what year was the first iPod sold?

285 What does 'tulipomania' refer to?

286 What is a Jigglypuff?

287 Atheophobia is the fear of:

288 Which artist took the most expensive photograph to date, Rhein II?

289 What is K-pop?

290 Who is the eldest member of the Backstreet Boys?

291 The Birkin bag is from which fashion brand?

292 How does 'Gossip Girl' sign off her messages?

293 What do young Swedish girls traditionally do during Midsummer's Eve?

294 IKEA-manufactured BILLY is:

295 What is the official language of Andorra?

296 Andy Warhol famously painted soup cans from which company?

297 In which city did the first Starbucks open iná1971?

298 In which two countries can you find more sheep than people?

299 What colour usually is a tin of Nivea creme?

300 How much alcohol by volume is typically in Sake?

301 In what year did UK TSB Bank split off from Lloyds TSB?

302 What instrument is featured on the coat of arms of Ireland?

303 What animal is featured on the back of the Greek $1 C ̧$ coin?

304 From which country do Claddagh rings originate?

305 In 'Jane Eyre', where does Mr Rochester live?

306 In what village in Yorkshire can you visit the Brontë parsonage?

307 What did U.S. President Theodore Roosevelt send around the world to demonstrate power?

308 According to hieroglyphics, what does the Egyptian goddess Isis' name mean?

$\begin{array}{ll}\text { Ulm } & \text { Princeton } \\ 1888 & 1945 \\ \text { Darmstadt } & \text { Wuppertal }\end{array}$

Chlorophyll

Cellulose

$X$ Approx. $1.4 \mathrm{~kg} / 3 \mathrm{lb} \quad$ Approx. $3 \mathrm{~kg} / 6.6 \mathrm{lb}$ 4

Gone With The

Wind

2001 1

A period where A mental disorder tulips were traded at extraordinary prices where individuals are obsessed with tulips

$\begin{array}{ll}\text { A Pokemon } & \text { A type of pastry } \\ \text { Atheists } & \text { Ducks }\end{array}$

Andreas Gursky Jeff Wall

$\begin{array}{ll}\begin{array}{ll}\text { A South Korean } \\ \text { music genre }\end{array} & \text { A sweet } \\ \text { Kevin Richardson } & \text { Chris Kirkpatrick } \\ \text { Hermès } & \text { Louis Vuitton } \\ \text { xoxo } & \text { xxx }\end{array}$

Pick seven flowers and jump over seven hedges in silence

$\begin{array}{ll}\text { A bookshelf } & \text { A desk } \\ \text { Catalan } & \text { Spanish } \\ \text { Campbell's } & \text { Heinz }\end{array}$

\section{Seattle}

Scotland \& New

Zealand

Blue

$15 \%$

Sing an ancient song

in a circle with

candles in their hands

A desk

Heinz

San Francisco

Ireland \& Poland

Orange

$40 \%$

2013

1995

A harp

A flute

Owl

Bull

Ireland

Thornfield Hall

Haworth

Scotland

Thrushcross Grange

Thornton

The Great White

Fleet

Throne

Surveillance Aircraft

Mother 
309 According to legend, where was King Arthur's sword Excalibur forged?

310 The Fourier transform is used to transform signals between which domains?

311 What is Stanford University's motto?

312 Which college did Barack Obama first attend before transferring to Columbia University?

313 What is gluten?

314 Who was awarded the first Nobel Prize in Physics in 1901 ?

315 What was Queen Victoria's opinion on make-up?

316 During which years was alcohol prohibited in the United States of America?

317 What does the Japanese word 'origami' translate as?

318 Which martial art is taught in the Israeli military?

319 Who produced the soundtrack for the film 'Despicable Me'?

320 Which individual has won the most Tony Awards, at 21?

321 Which film is currently ranked as the highest-grossing animated film of all time?

322 Where are Porsche's headquarters located?

323 Bentley, Bugatti, Lamborghini and Porsche all belong to which automotive company?

324 What is a Furby?

325 At what age did Kate Moss begin to model?

326 People of what religious faith celebrate Diwali?

327 In what century did the Brothers Grimm publish their first collection of fairy tales?

328 What is 'Bananagrams'?

329 What is the value of the letter $\mathrm{X}$ in the English language version of Scrabble?

330 From which country does the ice cream brand HäagenDazs originate?

331 In what year did Anna Wintour become editor-in-chief of American Vogue?

332 What is 86 degrees Fahrenheit in degrees Celsius?

333 In the Opening Ceremony of the 2012 Summer Olympic Games, how did Queen Elizabeth II supposedly arrive?

334 In the US sitcom Friends, what is the name of their often visited cafe?

335 What is the chemical formula for water?

\begin{tabular}{|c|c|}
\hline Avalon & Camelot \\
\hline Time and Frequency & $\begin{array}{l}\text { Amplitude and } \\
\text { Phase }\end{array}$ \\
\hline $\begin{array}{l}\text { "Die Luft der } \\
\text { Freiheit weht" - The } \\
\text { wind of freedom } \\
\text { blows. }\end{array}$ & $\begin{array}{l}\text { "Aien Aristeuein" - } \\
\text { Ever To Excel }\end{array}$ \\
\hline Occidental College & University of Dayton \\
\hline A protein composite & A sugar \\
\hline Wilhelm Röntgen & Max Planck \\
\hline $\begin{array}{l}\text { She publicly } \\
\text { declared it vulgar } \\
\text { and improper. } \\
1920-1933\end{array}$ & $\begin{array}{l}\text { She advocated its } \\
\text { use and praised its } \\
\text { effects. } \\
1918-1928\end{array}$ \\
\hline Folding of paper & $\begin{array}{l}\text { Creating beautiful } \\
\text { things }\end{array}$ \\
\hline Krav Maga & Karate \\
\hline Pharrell Williams & Jay-Z \\
\hline Harold Prince & Tommy Tune \\
\hline Frozen & The Lion King \\
\hline $\begin{array}{l}\text { Zuffenhausen, } \\
\text { Stuttgart } \\
\text { Volkswagen AG }\end{array}$ & $\begin{array}{l}\text { Untert }{ }^{3} \text { rkheim, } \\
\text { Stuttgart } \\
\text { General Motors }\end{array}$ \\
\hline $\begin{array}{l}\text { An electronic } \\
\text { robotic toy }\end{array}$ & A furry frisbee \\
\hline 14 & 16 \\
\hline Hinduism & Buddhism \\
\hline 19th century & 17th century \\
\hline A word game & A sugary drink \\
\hline 8 & 10 \\
\hline USA & Denmark \\
\hline 1988 & 1999 \\
\hline 30 & 20 \\
\hline $\begin{array}{l}\text { By jumping out of a } \\
\text { helicopter }\end{array}$ & $\begin{array}{l}\text { In a speedboat } \\
\text { driven up the } \\
\text { Thames }\end{array}$ \\
\hline Central Perk & Insomnia Cafe \\
\hline $\mathrm{H} 2 \mathrm{O}$ & $\mathrm{O} 2$ \\
\hline
\end{tabular}


336 What is Jordan's official language?

337 For how many years had Nelson Mandela been imprisoned before his release?

338 Out of 'wheelbarrow' and 'umbrella', which is a playing piece in the game monopoly?

339 The first astrological sign in the Zodiac, Aries, is represented by which animal?

340 Which originally Californian fast food chain lets customers order 'Animal Style fries' from their secret menu?

341 Who sang 'The Final Countdown'?

342 What does the Dormouse in 'Alice in Wonderland' struggle with?

343 What is South Park character Cartman's first name?

344 Who is the only character in the TV series 'Family Guy' with an English accent?

345 In which TV series did a whole season turn out to be a character's dream?

346 Who is Jenna Marbles?

347 Who is the world's largest zip manufacturer?

348 How are Huey, Dewey, and Louie Duck related to Donald Duck?

349 In his 1967 single, Louis Armstrong sang about what?

350 In the musical 'West Side Story', what is the female main character called?

351 What do mosses use to reproduce?

352 Shakespeare's Juliet lived in which city?

353 What did J.F. Kennedy proclaim in German when visiting Berlin in 1963?

354 Which artist wrote the words "Ceci n'est pas une pipe". (This is not a pipe) in his painting of a pipe?

355 What comparison by Irina Dunn is a popular feminist slogan?

356 What grain is porridge traditionally made from?

357 What did the Greek philosopher Diogenes of Sinope say about sunlight on meeting Alexander the Great?

358 Which member of the British royal family said "I'd like to be a queen of people's hearts"?

359 What is the English translation of the national motto of France?

360 Which philosopher said "I know that I know nothing?"

361 On what continent are the highest mountains in the world?

362 Which parent carries the fertilised eggs in seahorses?

363 What is a cat thought to show when twitching its tail from side to side?

364 What is a dog thought to show when wagging its tail?

365 What is the capital of France?

366 By process of brood parasitisation, the reed warbler is
Arabic

27

French

12

Wheelbarrow

Umbrella

Ram

Bull

In-N-Out Burger

Europe

Staying awake

Eric

Stewie

Dallas

A Youtube

personality

YKK group

They are his

nephews

A Wonderful World

Maria

Spores

Verona

"Ich bin ein

Berliner."

Magritte

"A woman needs a man like a fish needs a bicycle."

Oats

"Stand out of my sunlight."

Diana, Princess of

Wales

Freedom, Equality,

Brotherhood

Socrates

Asia

Father

Aggression

Joy or friendliness

Paris

Common cuckoo
Five Guys

David Bowie

Figuring out its birthday

Stan

Peter

Bonanza

A singer

ZIP group

They are his sons

Spanish Eyes

Bess

Seeds

Venice

"Ich bin ein

Amerikaner."

Matisse

"A woman needs a man like a pig needs wings."

Wheat

"Sunlight is the best disinfectant"

Camilla, Duchess of

Cornwall

Peace, Order, and

Good Government

Nietzsche

Africa

Mother

Joy

$\begin{array}{ll}\text { Aggression } & \mathrm{X} \\ \text { Madrid } & \mathrm{X}\end{array}$

Black-headed duck $x$

$x$ 
known to rear the young of which other species?

367 In Scotland, on what day of the year is St Andrew's Day celebrated?

368 What did Saint Martin of Tours share with a poor man?

30th November

His coat

Satisfaction

The Wall

Mein Kampf

Yes, we can.

A peanut butter and jelly sandwich

Speedy Gonzales

Yoga poses

Fat Man and Little

Boy

A sheep

9

Spine

John Cleese

BBC

Harold Pinter

1921

Mark Twain

1861

Jorge

Zurich

The Mediterranean

England and

Scotland

John Lennon

To copy it

Hoover

Top right

From right to left

Left

100

Scooby-Doo 17th March

His bread

Happiness

$x$

The Mall

X

My New Order $\quad \mathrm{X}$

Here I am.

$x$

A Peruvian Airline $\quad X$

Roadrunner

Constellations

Fat Boy and Little

Girl

A fox

8

Ear

Michael Palin

ITV

José Saramago

1935

Charles Dickens

1865

Gregoire

Geneva

The North Sea

Brazil and Uruguay

Paul McCartney

To destroy it

Harrison

Top left

From left to right

Right

1000

The Simpsons

396 How many centimetres are there in a metre?

397 Fred, Daphne, Velma and Shaggy are characters from 
which cartoon series?

398 Which TV series was set in the Stone Age town of Bedrock?

399 Pall Mall, Viceroy and Woodbine are all brands of what?

The Flintstones

Cigarette

Wiltshire

Glass

Cobalt

The time-travelling car in Back To The

Future

Darth Vader

Hasbro

Baddeley and Hitch

Malthus

Hooke

Pressure

Green

Mandelbrot

Blue

French

Sold

An Exit

Schroeder

How To Marry A

Millionaire

Omega

Red and blue wavelengths

Swedish

Peach Melba

3

Psycho

Dragon blood

Don Quixote

John Carpenter

General Knowledge
Stig Of The Dump

\section{X}

Chocolate

Somerset

Coal

Silver

The Death Star in Star Wars

Evil Emperor Zurg

Mattel

Craik and Tulving

Adam Smith

Boyle

The passing of time

Red

X

Kac

Red

Dutch

Selled

$x$

An Entrance

Linus

Some Like It Hot

Sigma

Green and blue

wavelengths

German

Peach Sundae

9
423 Which Alfred Hitchcock film was the most profitable?

424 In the epic poem 'Nibelungenlied', what does Siegfried bathe in to become invulnerable?

425 Which novel inspired the idiom 'tilting at windmills'?

426 Who in 1999 was the first US winner of 'Who Wants to be a Millionaire'?

427 What has been described by experts as 'culturally valued
The Birds

Unicorn blood

Krabat

Kim Hunt

Intelligence 
knowledge communicated by a range of non-specialist media'?

428 Which British quiz show features a spot-lit black chair from which contestants answer specialist and general knowledge questions?

429 From what is quorn made?

430 In Madame Bovary, what is the name of Emma's daughter?

431 What architectural feature do you walk through to enter a room?

432 About how long does fresh milk last in the refrigerator?

433 In the novel 'Sophie's World', what does the first anonymous postcard say?

434 How many teams took part in the 2010 Soccer World Cup?

435 What is ghee?

436 The Stanley Cup is contested in which sport?

Mastermind

EggHeads

Fungus

A door

About a week

Who are you?

32

Clarified butter

Ice hockey

140 characters

Random Access

Memory

Alexander Graham

Bell

3

Jake La Motta

Deafness

Deep Blue

2001

Pineapple

AC/DC

2.72

Hergé

Rubik's Cube

The right to remain silent

A language

Green

Selective Serotonin Reuptake Inhibitor

Ptolemy XII Auletes
Milk

Sophie

A window

$x$

About a month

Who made the world?

24

Sweet, spiced tea

Australian Rules

Football

160 characters

Raid Addressed

Microprocessor

Thomas Edison

81

Rocky Marciano

Blindness

Deep Sea

2003

Strawberry

Metallica

3.14

Goscinny and

Uderzo

Magic Box

The right to bear arms

An alcoholic spirit

White

Secondary

Somatostatin

Receptor loniser

Caesarion

$x$

$x$

$x$

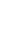


455 Which letter follows ' $M$ ' in the English alphabet?

456 Which computer company released the Sonic the Hedgehog video games series?

457 On what day of the Gregorian calendar does the Russian Orthodox Church celebrate Christmas?

458 Who is the author of the children's Adventure novel series featuring $\mathrm{Hal}$ and Roger Hunt?

459 What was the research programme that produced the first atomic bombs during World War II called?

460 What is Hopscotch?

461 What colour are British post boxes?

462 Which Coca Cola drink is specifically marketed to men?

463 Who sang 'Barbie Girl'?

464 From which country do the group O-Zone, who sang 'Dragostea din tei', originate?

465 What is the name of Angelina Jolie's adopted daughter?

466 Which member of the 'Made in Chelsea' cast formerly starred in 'The Hills'?

467 In which dystopian novel was Big Brother said to be watching citizens?

468 In which city is the stadium known as the 'Bird's Nest Stadium' located?

469 Mozzarella cheese is traditionally made with the milk of which animal?

470 Known as the 'hood' in American English, by what name is this part of a car known in British English?

471 What was Charlie Chaplin's middle name?

472 What was One Direction's first studio album called?

473 In which ocean are the Seychelles?

474 Which is the longest river in the world?

475 What is the name for a polygon with six sides?

476 What is the term for a young hare?

477 What is the term for a badger's home?

478 Whirlpool, Sombrero and Andromeda are all:

479 Of what species was the first mammal to be cloned?

480 In what country can the peak of Mount Kilimanjaro be found?

481 Relevant to the brain, what is CSF?

482 What is the capital of Indonesia?

483 Pewter is a metal alloy largely made up of which metal?

484 The 'hand of God' describes an infamous soccer incident perpetrated by which player?

485 St Patrick is said to have banished which animal from Ireland?

486 In what year was the Treaty of Versailles signed?

487 What is the capital of New Zealand?

488 A man who has lost his hair is said to be:
$\mathrm{N}$

Sega

7th January

Willard Price

The Manhattan

Project

A playground game

Red

Coke Zero

Aqua

Moldova

Zahara

Stephanie Pratt

1984

Beijing

Buffalo

Bonnet

Spencer

Up All Night

Indian

Nile

Hexagon

Leveret

Set

Galaxies

Sheep

Tanzania

Cerebro-Spinal Fluid

Jakarta

Tin

Diego Maradona

Snake

1919

Wellington

Bald
L

Atari

24th December

Arthur Ransome

SETI

A drink

Blue

Diet Coke

Fuego

Romania

Shiloh

Mark-Francis

Vandelli

Brave New World

Rio De Janeiro

Goat

Boot

Gladstone

Get Lucky

Pacific

Yangtze

Heptagon

Elver

Den

Bathroom fixture

manufacturers

Mouse

Mozambique

Cortico-Somatic

Function

Bangkok

Iron

Eric Cantona

Bear

1947

Auckland

Spent 
489 Which gland secretes the hormone insulin?

490 On a violin, what note is the string with the highest pitch?

491 Whereas trains runs on tracks, what do cars travel on?

492 What is the name of the place in which many people gather to watch a game of baseball?

493 The technology company Philips was founded in which country?

494 The Roman numeral D represents what number?

495 In what year did the Chernobyl nuclear disaster occur?

496 Who, in 1841, founded the first modern day travel agency?

497 Which Moomin character is mischievous, loves catastrophes and finds untidiness exciting?

498 Which Jewish festival is also called 'the feast of unleavened bread'?

499 What do vegans not eat?

500 What is the national dish of Portugal?
Pancreas

E

Roads

Stadium

The Netherlands

500

1986

Thomas Cook

Little My

Passover/Pesach

All animal products

and derivatives

Dried, Salted Cod
Adrenal

A

Rails

Rink

Great Britain

50

1989

James Cook

Snork Maiden

Yom Kippur

Vegetables

Note: Target and Lure indicate true and false response option. Exc. Indicates questions excluded based on the exclusion criteria detailed in the Methods. 


\section{Supplementary Materials B: Comparison of DP-RR and EV Model Fits}

The main body of the manuscript compares the fits of the dual process recollect-to-reject (DP-RR) model to the standard dual process (DP) and unequal variance (UEV) signal detection models. Whilst the DP-RR model is newly introduced in the manuscript, the DP and UEV models are widely accepted in the field as providing exceedingly good fits to episodic recognition data (e.g. O'Connor, Guhl, Cox \& Dobbins, 2011). However, the way in which these established models generate ROC is arguably disadvantaged by the fact that alterations to their parameters yield asymmetries in ROCs not evident in the semantic recognition data. It may be that a signal detection model constrained to produce symmetrical ROCs provides stronger competition for the DP-RR model.

One such model is the equal variance (EV) signal detection model - a model identical to the UEV model, but with the variance of the target distribution held constant at the same value of lure distribution variance. The EV model is a fundamental, minimally complex signal detection model, and parameterises recognition performance with only one distribution parameter, $d^{\prime}-$ the distance between the target and lure distribution means. When fitting an EV model ROC to data based on 6 degrees of confidence, 6 parameters can vary: 5 criterion parameters (one for each confidence boundary) and $d^{\prime}$.

When comparing models with differing parameter numbers, the model with the greater number of parameters has the most freedom with which to accommodate any given set of observations. Given the 6 parameters of the EV and 7 of the DP-RR model, log-likelihood (LL) fits would therefore tend to favour the DP-RR model. Methods by which the relative quality of models with unequal parameter numbers include the Akaike Information Criterion (AIC; Akaike, 1974). AIC penalises models for having more parameters, meaning that it is theoretically possible to use AIC to compare model fits whilst controlling for the inherent benefit accorded to models with more parameters. Whilst there are no hard and fast rules relating the magnitude of AIC difference to the degree to which one model is superior to another, Burnham and Anderson (2002) have proposed that a minimum difference of $2 \mathrm{AIC}$ units is required before the model returning the lower AIC value can be considered better fitting. In all eventualities, but especially in the absence of such a prominent AIC difference, it would be wise to consider the psychological plausibility of any model being fit to observed data. In the following analyses, we present a comparison of DP-RR and EV model fits, using both $L L$ and AIC statistics, to the data presented in the manuscript.

\section{EXPERIMENT 1}

Across all experiments, we fit data to the models in question using the procedures described in the manuscript. This holds for the EV model. As such, EV parameters and fit statistics described in this document result from a MLE fitting procedure analogous to that used for the DP-RR and other competing models.

Figure S1 shows the averaged ROCs for the full and question-selective data subsets. Whilst both models are constrained to fit only symmetric ROCs, the EV model's constraint to start at the origin $[0,0]$ and end at $[1,1]$ causes a prominent ROC overshoot, as was evident in the similarly constrained UEV model's average ROCs (Figures 2 and 5). 
A
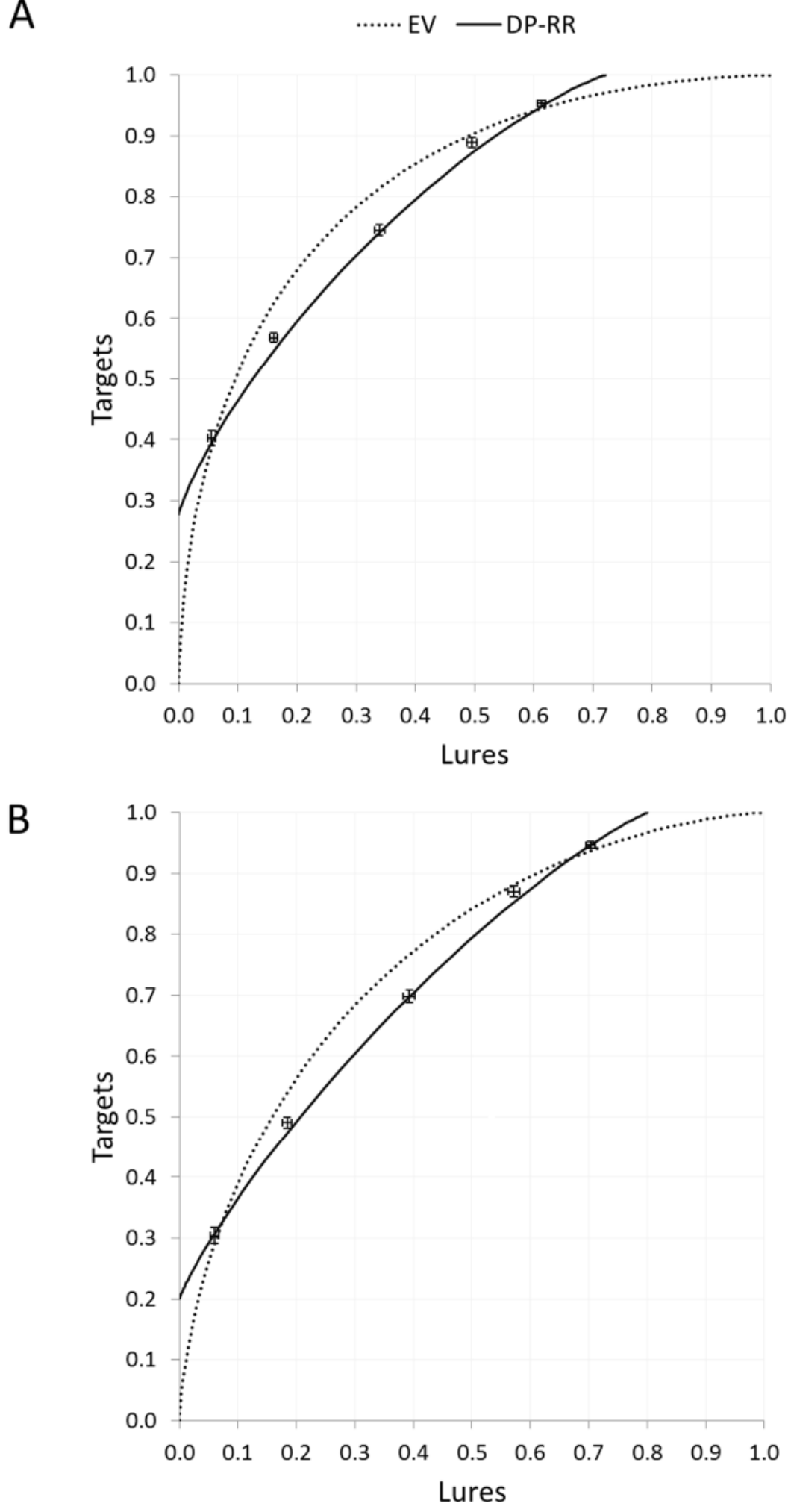

Figure S1: Experiment 1 observed data and mean fits from EV and DP-RR models.

The five points shown at the intersection of their respective $95 \% \mathrm{Cls}$ on the ROC plots represent the mean observed ROC points. The two lines are constructed using the mean parameters recovered when participants are fit individually, with the EV model shown as a dotted line, and the DP-RR model shown as a solid line. Panel A shows data and fits from the full dataset. Panel B shows data and fits from the question-selective subset. 
Turning to fit statistics, as would be expected from a model with fewer parameters, the DP-RR model's mean LLs were significantly higher (less negative) than the EV model's mean LLs in both the full and question selective data subsets: Full DP-RR -79.69 [-80.79 -78.59], Full EV -81.00 [-82.11 79.89], $t(501)=21.31, p<.001, d=.951$; Question-selective DP-RR -67.91 [-68.92 -66.90], Questionselective EV -78.94 [-69.96 -67.93], $t(499)=20.08, p<.001, d=.898$. The superiority of the DP-RR model's overall capacity to accommodate the data echoes its superiority in visual comparisons of Figure S1.

The more important comparison is of the AIC statistics. As was previously described, a lower AIC is indicative of a better-fitting model once the number of parameters have been accounted for. In both data subsets, there were numeric advantages favouring the DP-RR fits over the EV fits, though there was only a significant difference between the means in the full dataset: Full DP-RR 173.39 [171.19 175.59], Full EV 174.00 [171.79 176.21], $t(501)=-5.01, p<.001, d=.223$; Question-selective DP-RR 149.81 [147.79 151.83], Question-selective EV 149.88 [147.85 151.91], $t(499)=.681, \mathrm{p}=.496, d=$ .030. These AIC differences suggest that, even when controlled for the number of parameters used in each model, there is a very slight advantage for the DP-RR model in fitting the semantic data from Experiment 1.

We now turn to the same comparison for the episodic and semantic data obtained in Experiment 2. This is of particular interest given that it provides context for the comparison of the model fits to the novel semantic procedure, in the form of model fits to episodic recognition. In episodic recognition, the unequal variance (UEV) signal detection model is regarded as providing fits far superior to the EV model (e.g. Yonelinas, Dobbins, Szymanski, Dhaliwal, \& King, 1996).

\section{EXPERIMENT 2}

Figure S2 shows the averaged ROCs for the semantic and episodic data, in full and sensitivitymatches subsamples.

Across full and sensitivity-matched subsamples, the DP-RR means fits show closer correspondence to the observed semantic data than the EV fits. Interestingly, the fit superiority is less clear-cut for the episodic data, especially for the full sample.

Formal comparison of $L L$ statistics in the semantic data found once again that the DP-RR model's mean LLs were significantly higher than the EV model's: Full DP-RR -67.13 [-68.45 -65.81], Full EV $68.02[-69.36-66,74], t(308)=14.10, p<.001, d=.802$; Sensitivity-matched DP-RR -65.93 [-67.81 64.05], Sensitivity-matched EV -66.63 [-68.54 -64.72], $t(108)=8.15, p<.001, d=.780$. When penalising for the number of parameters using the AIC statistic though, the EV model had the numerical advantage in producing lower means, with a significant difference in the sensitivitymatched subsample: Full DP-RR 148.27 [145.63 150.91], Full EV 148.03 [145.35 150.72], $t(308)=$ $1.874, p=.062, d=.107$; Sensitivity-matched DP-RR 145.86 [142.10 149.63], Sensitivity-matched EV $145.26[141.44149 .08], t(108)=3.52 ., p=.001, d=.337$. 
A
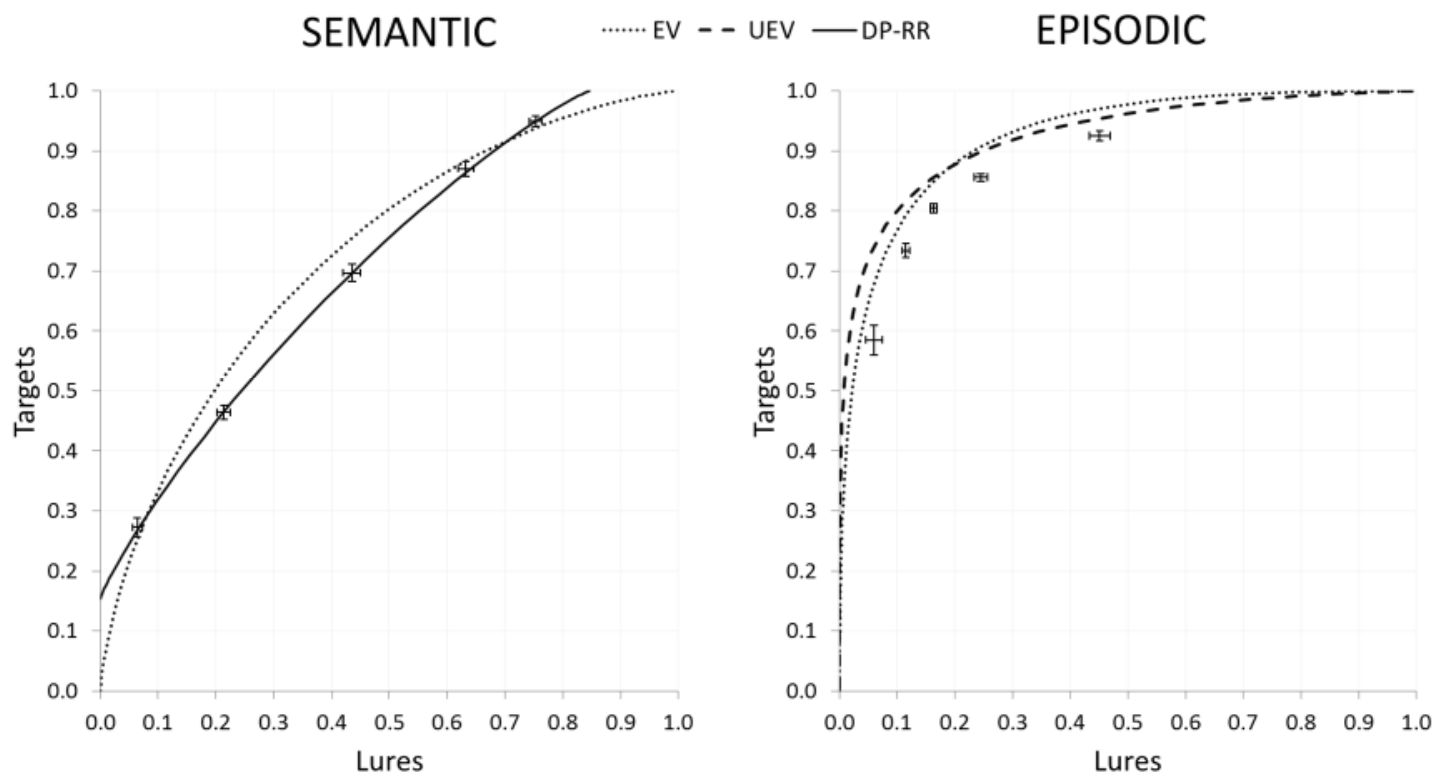

B
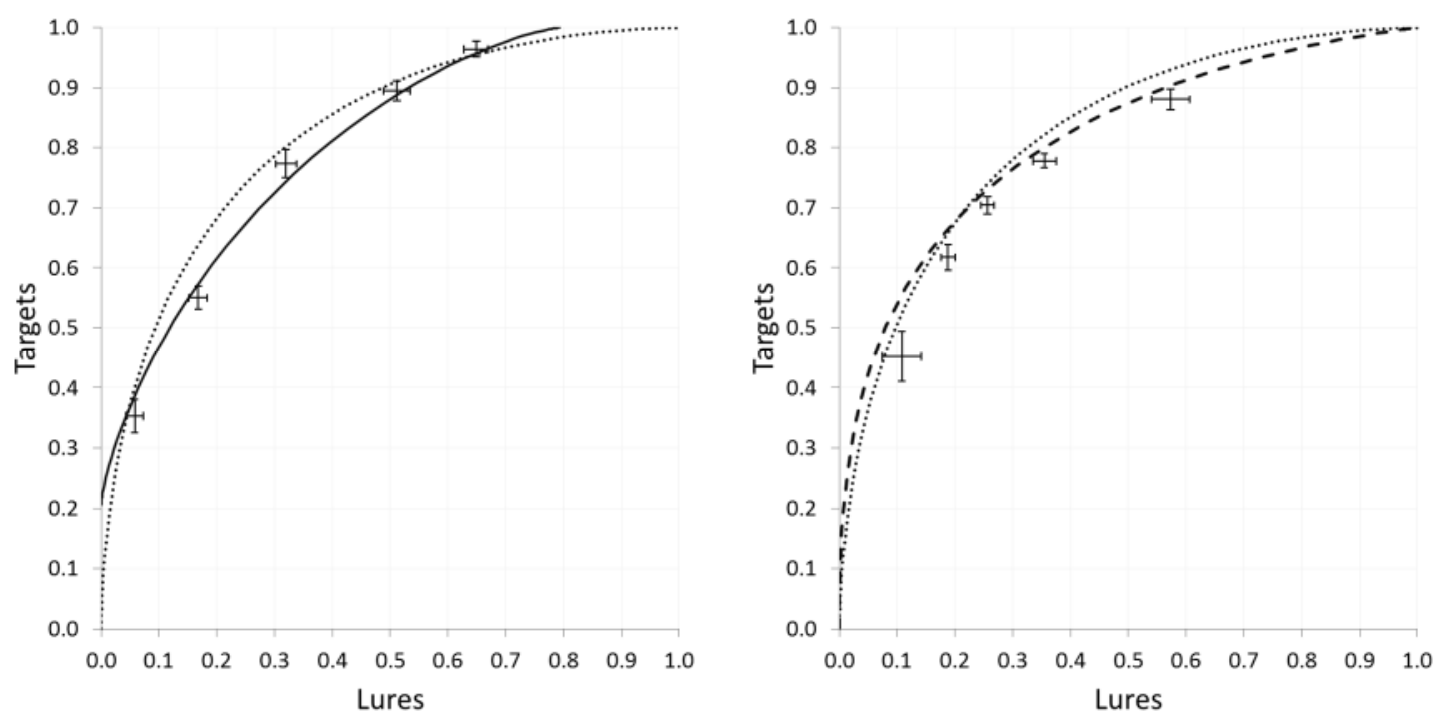

Figure S2: Experiment 2 observed data and mean fits to semantic and episodic data from EV, UEV and DP-RR models.

The five points at the intersections of their $95 \%$ Cls represent the means observed ROC points. The lines are constructed using the mean parameters recovered for the DP-RR (semantic data), UEV (episodic data) and EV (semantic and episodic data) signal detection models. Panel A shows fits to the full sample of participants. Panel B shows fits to the sensitivity-matched subsamples. The lefthand-side of panels shows semantic data fits, the right-hand-side shows episodic data fits. 
The comparison of the UEV against the EV models in the episodic data yielded significant advantages for the UEV model in $L L$ parameters: Full UEV -107.41 [-110.41 -104.13], Full EV -108.16 [-111.45 $104.87], t(279)=12.66, p<.001, d=.756$; Sensitivity-matched UEV -123.96 [-128.66 -119.27], Sensitivity-matched EV -124.53 [-129.24 -119.82], $t(107)=8.11, p<.001, d=.780$. Notably, the EV model was superior according to AIC statistics, in both full and sensitivity matched samples: Full UEV 228.82 [222.25 235.39], Full EV 228.31 [221.73 234.90], $t(279)=4,33, p<.001, d=.259$; Sensitivitymatched UEV 261.93 [252.93 271.33], Sensitivity-matched EV 261.06 [251.65 270.48], $t(107)=6.22$, $p<.001, d=.599$.

Taken together these comparisons suggest that DP-RR and UEV, models with a single more parameter than the EV model, fit their respective data better when $L L$ statistics are compared. However, the AIC comparisons tend to favour the more sparsely parameterised EV model across both semantic and episodic domains. The lack of an advantage for the UEV model in the episodic domain is noteworthy. Episodic recognition memory researchers have widely discontinued consideration of the EV model as a viable model when compared to UEV (and DP) models. That it continues to show an advantage in the data from Experiment 2 perhaps reflects an over-penalisation of models for additional parameters by the AIC statistic, especially when theoretical considerations that synthesise findings across a range of paradigms are brought to bear on the argument. Beyond this theoretical consideration, quite how much weight should be given to the (sometimes significant) numeric AIC differences of less than one unit across both semantic and episodic domains remains open to interpretation (see Burnham \& Anderson, 2002).

In summary, when the semantic data over Experiments 1 and 2 are examined, the DP-RR model does not appear to be compellingly superior to the EV model. However, in the context of the episodic data from Experiment 2 relative to the current position of the recognition memory literature, and the caveat that small differences in AIC should not mask arguments of theoretical superiority, it is not clear that the EV model should be considered alongside the models reviewed in the manuscript as a viable model for recognition memory.

\section{REFERENCES}

Akaike, H. (1974). A new look at the statistical model identification. IEEE Transactions on Automatic Control, 19, 716-723. http://dx.doi.org/10.1109/TAC.1974.1100705

Burnham, K.P. \& Anderson, D. R. (2002). Model Selection and Multimodel Inference: A Practical Information-Theoretic Approach (2nd ed.). New York: Springer-Verlag. http://dx.doi.org/10.1007/b97636

O'Connor, A.R., Guhl, E.N., Cox, J.C. \& Dobbins, I.G. (2011). Some memories are odder than others: Judgments of episodic oddity violate known decision rules. Journal of Memory and Language, 64, 299-315. http://dx.doi.org/10.1016/i.jml.2011.02.001

Yonelinas, A.P., Dobbins, I., Szymanski, M.D., Dhaliwal, H.S., \& King, L. (1996). Signal-detection, threshold, and dual-process models of recognition memory: ROCs and conscious recollection. Consciousness and cognition, 5(4), 418-441. http://dx.doi.org/10.1006/ccog.1996.0026 